\title{
MONETARY POLICY AND THE ASSET RISK-TAKING CHANNEL
}

Angela Abbate and Dominil thaler

Documentos de Trabajo. N. 1805

\section{BANCODE ESPAÑA}

\author{
Eurosistema
}

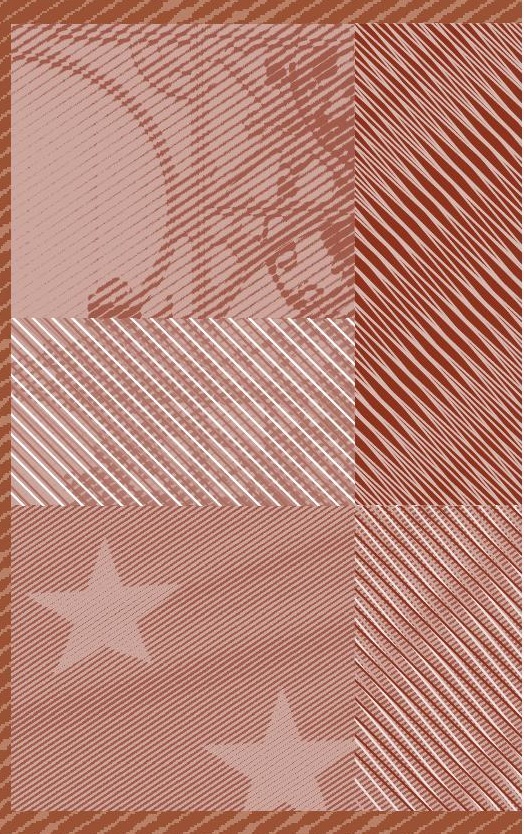


MONETARY POLICY AND THE ASSET RISK-TAKING CHANNEL 
MONETARY POLICY AND THE ASSET RISK-TAKING CHANNEL

\author{
Angela Abbate ${ }^{(* *)}$ \\ SWISS NATIONAL BANK \\ Dominik Thaler ${ }^{(* \star)}$ \\ BANCO DE ESPAÑA
}

$\left.{ }^{\star}{ }^{\star}\right)$ The authors would like to thank Arpad Abraham, Pelin llbas, Ester Faia, Stéphane Moyen, Evi Pappa, Raf Wouters, our colleagues at the Bundesbank, European University Institute and National Bank of Belgium, as well as participants to the Applied Time Series Econometrics Workshop in St. Louis, XX Workshop on Dynamic Macroecomics in Vigo and to the $6^{\text {th }}$ Bundesbank-CFS-ECB Workshop on Macro and Finance in Frankfurt and three anonymous referees for useful comments. We thank the NBB for funding Dominik Thaler's research stay in Brussels. This paper represents the authors' personal opinions and does not necessarily reflect the views of the Deutsche Bundesbank, the Swiss National Bank, the Banco de España or their staff.

${ }^{* *}$ Swiss National Bank, Angela.Abbate@snb.ch.

$\left.{ }^{(\star \star}\right)$ Banco de España, dominik.thaler@eui.eu. 
The Working Paper Series seeks to disseminate original research in economics and finance. All papers have been anonymously refereed. By publishing these papers, the Banco de España aims to contribute to economic analysis and, in particular, to knowledge of the Spanish economy and its international environment.

The opinions and analyses in the Working Paper Series are the responsibility of the authors and, therefore, do not necessarily coincide with those of the Banco de España or the Eurosystem.

The Banco de España disseminates its main reports and most of its publications via the Internet at the following website: http://www.bde.es.

Reproduction for educational and non-commercial purposes is permitted provided that the source is acknowledged.

C BANCO DE ESPAÑA, Madrid, 2018

ISSN: 1579-8666 (on line) 


\section{Abstract}

How important is the risk-taking channel for monetary policy? To answer this question, we develop and estimate a quantitative monetary DSGE model where banks choose excessively risky investments, due to an agency problem which distorts banks' incentives. As the real interest rate declines, these distortions become more important and excessive risk taking increases, lowering the efficiency of investment. We show that this novel transmission channel generates a new and quantitatively significant monetary policy trade-off between inflation and real interest rate stabilization: it is optimal for the central bank to tolerate greater inflation volatility in exchange for lower risk taking.

Keywords: bank risk, monetary policy, DSGE models.

JEL classification: E12, E44, E58. 


\section{Resumen}

¿Cuánto importa el canal de toma de riesgos (risk-taking channel) para la política monetaria? Para responder a esta pregunta, desarrollamos y estimamos un modelo cuantitativo macroeconómico DSGE, en el que los bancos eligen inversiones excesivamente arriesgadas, debido a un problema de agencia que distorsiona los incentivos de los bancos. Cuando el tipo de interés real baja, el peso de esas distorsiones aumenta y los bancos toman más riesgos, lo cual tiene un impacto negativo sobre la eficiencia de sus inversiones. Demostramos que este nuevo canal de transmisión genera un nuevo y cuantitativamente significativo trade-off entre la estabilización de la inflación y los tipos de interés: para el banco central resulta deseable aceptar más volatilidad de inflación a cambio de menos toma de riesgos.

Palabras clave: riesgo bancario, política monetaria, modelos DSGE.

Códigos JEL: E12, E44, E58. 


\section{Introduction}

The recent financial crisis has sparked a debate about the influence of monetary policy on the risk-taking behavior of the banking sector. A number of recent studies such as Jimenez et al. (2014) show that low interest rates increase the risk appetite of banks, creating an additional channel of monetary policy transmission, known as the risk-taking channel. ${ }^{1}$ Though there has been much discussion of the risk-taking channel amongst policy makers in recent years, ${ }^{2}$ its general-equilibrium and optimal monetary-policy implications remain unclear. Answering these questions requires a quantitative model which is consistent with both the evidence on the risk-taking channel and with conventional views about monetary policy. Our contribution is to build and estimate a medium-scale New Keynesian DSGE model, where monetary policy influences bank risk taking, which in turn affects the real economy. Furthermore, we provide analytical results which show how the inefficiency of risk taking depends on the volatility of the real interest rate, implying a motive for the policy maker to stabilize the real interest rate, at the cost of greater inflation volatility. This constitutes a new trade-off that influences optimal monetary policy in a quantitatively significant way.

In our model banks raise funds through deposit and equity, which they then use to invest in risky capital projects. In particular, banks choose from a continuum of investment projects, each defined by different risk-return characteristics. Every project has a certain probability of being successful and yielding capital in the next period. However, the safer the project, the lower the return in the event of success. As in Dell'Ariccia et al. (2014), we assume that depositors cannot observe the investment risk choice and that bank owners are protected by limited liability. These two assumptions create an agency problem: banks are partially isolated from the downside risk of their investment and choose a risk level that is socially excessive. ${ }^{3}$ The agency problem could be mitigated if bankers held more equity. Yet, banks rely on both types of funding because equity is relatively more costly than deposits due to deposit insurance and a friction in the equity market. A lower risk-free rate increases the relative cost advantage of deposits. Banks respond by levering up and choosing riskier investment projects. This higher risk implies a lower average efficiency of investment, which leads to a decline in the capital stock. Our model hence generates a new transmission channel through which monetary policy affects the real economy. This channel dampens the positive effects of expansionary

\footnotetext{
${ }^{1}$ This term was first used by Borio and Zhu (2008).

${ }^{2}$ See, for instance, New York Times, 'Fed officially concedes risk of low rates but signals no shift', 11.10.2010, Financial Times, 'Draghi warns central banks against blind risk taking', 14.5.2015, Bloomberg Business, 'Carney says QE can encourage excessive risk taking in financial markets', 25.1.2015.

${ }^{3}$ By socially excessive we mean that it exceeds the risk level that would be chosen, if no friction were present.
} 
monetary policy, as reductions in the interest rate exacerbate the financial market distortions and their implied inefficiency. We validate the quantitative implications of the model by estimating it on US data. Posterior odds show that the inclusion of the risk-taking channel improves the in-sample fit for nonfinancial variables. At the same time our model predicts a path of risk taking that matches survey evidence on the riskiness of newly issued loans from the Fed Survey of Terms of Business Lending.

We use the model to analyze the normative implications of the risk-taking channel for monetary policy, and their quantitative importance in terms of consumer welfare. First we show how the risk-taking channel generates a new trade-off between inflation stabilization, the objective arising from price stickiness in New Keynesian models, and interest rate stabilization, a new objective which arises from the risk-taking channel. As we demonstrate theoretically, the volatility of the real interest rate decreases the average efficiency of the banks' risk choice. Hence, by stabilizing the real interest rate the central bank can ameliorate the inefficiency in the financial sector. This however requires more muted responses of the interest rate to inflation deviations. Thus, stabilizing banking sector fluctuations comes at the expense of allowing greater inflation volatility.

Moreover, we show that this new objective alters optimal policy in a quantitatively significant way. Using optimal simple rules, we find that the central bank optimally accepts around $50 \%$ more inflation volatility relative to the case without the risk-taking channel, in return for a more stable real interest rate. Furthermore, ignoring the risk-taking channel comes at a welfare cost equivalent to a $0.5-1.0 \%$ loss in lifetime consumption. These results complement existing findings for other general-equilibrium models with financial frictions such as De Fiore and Tristani (2013) and Bernanke and Gertler (2001), where optimal policy remains close to full price stability even if financial frictions are introduced. In particular, De Fiore and Tristani (2013) characterize Ramsey policy in a small New Keynesian set-up with credit frictions, where firms borrow in advance to pay wages, and where default risk and costly monitoring generate a spread between the loan rate and the risk-free rate. The authors show that the presence of credit frictions augments the otherwise standard second-order approximation of the welfare function with one additional term: i.e. that interest-rate and credit-spread volatility directly influence welfare. However, this additional term is found to be quantitatively small, so that optimal policy does not substantially deviate from price stability.

Our work relates to a growing theoretical literature that links monetary policy to financial sector risk in a general-equilibrium framework. Yet, several features distinguish our work from existing ones. First, motivated by the evidence reviewed above, it is the first to explicitly model the effect of monetary policy on the riskiness of banks' assets and its macroeconomic effects. Second, we show theoretically 
how the risk-taking channel generates a new significant trade-off for the monetary policy authority. Most of the existing literature explores risk on the funding side of banks' balance sheets, associating risk with increased leverage. For instance, several models build on the financial accelerator framework of Bernanke et al. (1999). ${ }^{4}$ The mechanism in these models relies on the buffer role of equity, and therefore leverage is found to be counter-cyclical with respect to the balance sheet size. Our model, by contrast, gives rise to pro-cyclical leverage, which is in line with the empirical evidence reported in Adrian and Shin (2014) and Adrian et al. (2015). Another example is Angeloni and Faia (2013) and Angeloni et al. (2015), where lower interest rates translate into a higher bank leverage, and a higher fraction of inefficient bank runs. Asset risk, on the other hand, has so far mainly been discussed in the literature on optimal regulation such as Christensen et al. (2011) and Collard et al. (2012). In these papers, however, either the depositors or the financial regulator ensure that risk is always chosen optimally, so monetary policy has no influence on risk taking. ${ }^{5}$ In contrast to the previous two papers, we provide micro-foundations for the asset risk-taking channel and focus on monetary policy while abstracting from regulation. ${ }^{6}$

Our model of the asset risk-taking channel explains two stylized facts documented by recent empirical evidence. First, low interest rates cause banks to make riskier investments. Using micro data from the Spanish Credit Register, Jimenez et al. (2014) find that lower interest rates induce banks to make relatively more loans to firms that qualify as risky ex ante as well as ex post. ${ }^{7}$ Second, the increase in risk taking is not fully compensated for by higher risk premia on loans, as shown by Buch et al. (2014) and Ioannidou et al. (2014). As a consequence, the expected return on banks' investment decreases, as risk increases in response to lower interest rates. Moreover, the model posits that the banks' asset risk choice is determined by the level of leverage, rather than the quantity of loans: a modeling choice which is in line with the findings of Ioannidou et al. (2014) and Jimenez et al. (2014).

The paper is structured as follows. In Section 2 we develop a DSGE model of the asset risk-taking channel. Section 3 presents the results from the estimation of the model and discusses the dynamic implications of bank risk taking. Section 4 analyzes how monetary policy should be conducted if the risk-taking channel is present, and Section 5 concludes.

\footnotetext{
${ }^{4}$ For example, in Gertler et al. (2012) and de Groot (2014) a monetary expansion increases banking sector leverage, which in turn amplifies the financial accelerator and strengthens the propagation of shocks to the real economy.

${ }^{5}$ Both papers feature ad-hoc extensions that relate risk to the amount of lending and hence indirectly to monetary policy.

${ }^{6}$ One could reinterpret our model as applying to an economy where regulation is unable to fully control risk taking.

7This finding is confirmed by Dell'Ariccia et al. (2013), Angeloni et al. (2015), Afanasyeva and Guentner (2015) and Buch et al. (2014) for the US and by Ioannidou et al. (2014) for Bolivia.
} 


\section{A Dynamic New Keynesian model with a bank risk-taking channel}

We build a general-equilibrium model where competitive banks obtain funds from depositors and equity holders, and invest them into capital projects executed by capital producers. Every bank chooses its investment from a continuum of technologies, each defined by a given risk-return characteristic. The risk choice of the bank is distorted by an agency problem and affected by the level of the real interest rate. This model reproduces two features found in the data: risk taking depends on the contemporaneous interest rate and is not fully reflected in risk premia. The non-financial sectors of the economy feature standard elements as in Smets and Wouters (2007), and are therefore sketched only briefly here. More details on the standard sectors and the complete set of equations characterizing the model can be found in Appendix B.

\subsection{Households}

The representative household chooses consumption $c_{t}$, working hours $L_{t}$ and savings in order to maximize its discounted lifetime utility. Saving is possible through three instruments: government bonds $s_{t}$, which pay the safe gross nominal interest rate $R_{t}$, deposit funds $d_{t}$, and bank equity funds $e_{t}$. The two funds enable the household to invest into the banking sector, and pay an uncertain nominal return of $R_{d, t+1}$ and $R_{e, t+1} \cdot{ }^{8}$ Maximization of his lifetime utility (see Appendix B) yields the usual labor supply condition, the Euler equation, and two no-arbitrage conditions:

$$
\begin{aligned}
& E_{t}\left[\Lambda_{t+1} \frac{R_{d, t+1}}{\pi_{t+1}}\right]=E_{t}\left[\Lambda_{t+1} \frac{R_{t}}{\pi_{t+1}}\right], \\
& E_{t}\left[\Lambda_{t+1} \frac{R_{e, t+1}}{\pi_{t+1}}\right]=E_{t}\left[\Lambda_{t+1} \frac{R_{t}}{\pi_{t+1}}\right],
\end{aligned}
$$

where $\Lambda_{t}$ is the marginal utility of consumption.

\subsection{Equity and deposit funds}

As we explain in detail below, there is a continuum of banks which intermediate the households' savings using deposits and equity. Each bank is subject to a binary idiosyncratic shock which makes a bank fail with probability $1-q_{t-1}$, in which case equity is wiped out completely and depositors receive partial compensation from the deposit insurance scheme. We assume that households invest into bank

\footnotetext{
${ }^{8}$ In our notation the time index refers to the period when a variable is determined.
} 
equity and deposits through two funds, which diversify away the idiosyncratic bank default risk by investing into all banks. ${ }^{9}$

The deposit fund works without frictions, and represents the depositors' interests perfectly. It raises money from the households and invests it into $d_{t}$ units of deposits. ${ }^{10}$ In the next period, the fund receives the nominal deposit rate $r_{d, t}$ from each bank that does not fail. Deposits of failing banks are partially covered by deposit insurance. Most deposit insurance schemes around the world, including the US, guarantee all deposits up to a certain maximum amount per depositor. ${ }^{11}$ We model this capped insurance scheme by assuming that the deposit insurance guarantees deposits up to a fraction $\psi$ of total bank liabilities $e_{t}+d_{t}{ }^{12}$ We assume that the deposit insurance cap is inflation-adjusted, to avoid complicating the monetary policy trade-off by allowing an interdependence between monetary policy and deposit insurance. As we will show later, the deposit insurance cap is always binding in equilibrium, i.e. the bank's liabilities exceed the cap of the insurance $r_{d, t} d_{t}>\psi\left(d_{t}+e_{t}\right) \pi_{t+1}$. Defining the equity ratio $k_{t}=\frac{e_{t}}{d_{t}+e_{t}}$, the deposit fund therefore receives a real return of $\psi /\left(1-k_{t}\right)$ per unit of deposits from each defaulting bank at $t$. The deposit fund hence pays a nominal return of:

$$
R_{d, t+1} \equiv q_{t} r_{d, t}+\left(1-q_{t}\right) \frac{\psi}{1-k_{t}} \pi_{t+1}
$$

Unlike the deposit fund, the equity fund is subject to a simple agency problem. ${ }^{13}$ In particular, we assume that the fund manager faces two options. He can behave diligently and use the funds raised at $t$ to invest into $e_{t}$ units of bank equity. A fraction $q_{t}$ of banks pay back a return of $r_{e, t+1}$ next period, while defaulting banks pay nothing. Alternatively, the fund manager can abscond with the funds and consume a fraction $\xi_{t}$ in the subsequent period, while the rest is lost. To prevent the fund manager from doing so, the equity providers promise to pay him a premium $p_{t}$ at time $t+1$ conditional on not absconding. Equity providers pay the minimal premium that induces diligent behavior, i.e. $p_{t}=\xi_{t} e_{t}$. This premium is rebated to the household in a lump-sum fashion. Once absconding is ruled out

\footnotetext{
${ }^{9}$ Focusing on idiosyncratic risk is a simplification that keeps the model tractable. In a previous version of this paper we considered an extension where the default rate is stochastic and its volatility increasing in the idiosyncratic risk choice. We found that this strengthened the quantitative implications for monetary policy that we discuss below.

${ }^{10}$ We use deposits to refer to both units of deposit funds and units of bank deposits since they are equal. We do the same for equity.

${ }^{11}$ For a comprehensive documentation see, for instance, Demirgüç-Kunt et al. (2005).

${ }^{12}$ We introduce deposit insurance to be able to explain the high levels of bank leverage prevalent in the data. For further discussion of the deposit insurance modeling choices, see footnote 36 .

${ }^{13}$ Households are assumed not to be able invest into bank equity other than through the equity fund, as they may be to small to be able to diversify their investment effectively, or as they may lack the information on how to manage equity investment effectively). This ensures that the friction at the equity fund generates the excess equity premium.
} 
in equilibrium, the equity fund manager perfectly represents the interests of the equity providers. The equity fund hence pays the return on bank equity net of the premium:

$$
R_{e, t+1} \equiv q_{t} r_{e, t+1}-\xi_{t} \pi_{t+1} .
$$

We allow the equity premium $\xi_{t}$ to vary over time. ${ }^{14}$ Since bank equity is the residual income claimant, the return on the equity fund is affected by all types of aggregate risk that influences the return of surviving banks.

The two financial distortions introduced so far have important implications. The agency problem implies an (excess) equity premium, i.e. a premium of the risk-adjusted return on equity over the risk-free rate. Deposit insurance, on the other hand, acts as a subsidy on deposits, which implies a discount on the riskadjusted return on deposits. As explained below, the difference in the costs of these two funding types induces a meaningful trade-off between bank equity and bank deposits under limited liability.

\subsection{Capital producers}

We assume that the capital production process is risky in a way that nests the standard capital production process in the New Keynesian model. In particular, capital is produced by a continuum of capital producers indexed by $m$. At period $t$ they invest $i_{t}^{m}$ units of final good into a capital project of size $o_{t}^{m}$. This project is successful with probability $q_{t}^{m}$, in which case the project yields $\left(\omega_{1}-\frac{\omega_{2}}{2} q_{t}^{m}\right) o_{t}^{m}$ units of capital at $t+1$. Otherwise, the project fails and only the liquidation value of $\theta o_{t}^{m}$ units of capital can be recovered (where $\theta \ll \omega_{1}-\frac{\omega_{2}}{2} q_{t}^{m}$ ). Each capital producer has access to a continuum of technologies with different risk-return characteristics indexed by $q^{m} \in[0,1]$. Given a certain technology $q_{t}^{m}$, the output of producer $m$ is therefore:

$$
K_{t}^{m}= \begin{cases}\left(\omega_{1}-\frac{\omega_{2}}{2} q_{t}^{m}\right) o_{t}^{m} & \text { with probablity } q_{t}^{m} \\ \theta o_{t}^{m} & \text { else }\end{cases}
$$

This implies that the safer the technology (higher $q_{t}^{m}$ ), the lower is output in the event of success.

Each bank orders one capital project, and requires the capital producer to use a certain technology, but this choice cannot be observed by any third party. Given the technology choice $q_{t}$, and assuming that the projects of individual producers are uncorrelated, we can exploit the law of large numbers to derive aggregate capital:

\footnotetext{
${ }^{14}$ This shock, driving a wedge between deposit and safe rates on one hand, and equity rates on the other, is similar to the risk premium shock often found in medium-scale DSGE models (e.g. Smets and Wouters (2007)). Like all shocks in the model, it follows a standard lognormal $\mathrm{AR}(1)$ process.
} 


$$
K_{t}=o_{t}\left(q_{t}\left(\omega_{1}-\frac{\omega_{2}}{2} q_{t}\right)+\left(1-q_{t}\right) \theta\right) .
$$

Furthermore we assume that capital, which depreciates at rate $\delta$, becomes a project (of undefined $q_{t}$ ) at the end of every period. That is, existing capital may be destroyed due to unsuccessful reuse, and it can be reused under a different technology than it was originally produced. ${ }^{15}$

The total supply of capital projects by the capital producers is the sum of the existing capital projects $o_{t}^{\text {old }}=(1-\delta) K_{t-1}$, which they purchase from the owners (the banks) at the real price $Q_{t}$, and the newly created projects $o_{t}^{\text {new }}$, which are created by investing $i_{t}$ units of the final good. We allow for investment adjustment costs and investment efficiency shocks, i.e. we assume that $i_{t}$ units of investment yield $\varepsilon_{t}^{I}\left(1-S\left(i_{t} / i_{t-1}\right)\right)$ units of project, where $S=\kappa\left(\frac{i_{t}}{i_{t-1}}-1\right)^{2}$. Hence $o_{t}=o_{t}^{\text {new }}+o_{t}^{\text {old }}$ and $o_{t}^{\text {new }}=\varepsilon_{t}^{I}\left(1-S\left(\frac{i_{t}}{i_{t-1}}\right)\right) i_{t}$. Capital producers maximize their expected discounted profits taking as given the price $Q_{t}$ and the household's stochastic discount factor: ${ }^{16}$

$$
\max _{i_{t}, o_{t}^{\text {old }}} E_{t} \sum_{0}^{\infty} \beta^{t} \Lambda_{t}\left[Q_{t} \varepsilon_{t}^{I}\left(1-S\left(\frac{i_{t}}{i_{t-1}}\right)\right) i_{t}+Q_{t} o_{t}^{\text {old }}-i_{t}-Q_{t} o_{t}^{\text {old }}\right] .
$$

While the old capital projects are always reused, the marginal capital project is always a new one. ${ }^{17}$ Hence, the price of projects $Q_{t}$ is determined by new projects according to the well known Tobin's q equation:

$Q_{t} \varepsilon_{t}^{I}\left[1-S\left(\frac{i_{t}}{i_{t-1}}\right)-S^{\prime}\left(\frac{i_{t}}{i_{t-1}}\right) \frac{i_{t}}{i_{t-1}}\right]-1=\beta E_{t}\left[\frac{\Lambda_{t+1}}{\Lambda_{t}} \varepsilon_{t+1}^{I} Q_{t+1} S^{\prime}\left(\frac{i_{t+1}}{i_{t}}\right)\left(\frac{i_{t+1}}{i_{t}}\right)^{2}\right]$.

Note that our model of risky capital production boils down to the standard riskless setting of the New Keynesian model if we fix $q_{t}=\bar{q}$ and choose parameters such that $q_{t}\left(\omega_{1}-\frac{\omega_{2}}{2} q_{t}\right)+\left(1-q_{t}\right) \theta=1$.

\subsection{The Bank}

The bank is the central agent of our model: it raises resources through deposits and equity and invests them into a risky project. As in Dell'Ariccia et al. (2014), an agency problem arises between banks and depositors when choosing the risk level, since depositors cannot observe the banks' risk choice and banks are protected

\footnotetext{
${ }^{15}$ This assumption ensures that we do not have to keep track of the distribution of different project types. Think of a project as a machine yielding capital services, which can be run at different speeds (levels of risk). In case it is run at a higher speed, the probability of an accident destroying the machine is higher. After each period the existing machines are overhauled by the capital producers and at this point the speed setting can be changed.

${ }^{16}$ Their out-of-steady-state profits are rebated lump sum to the household.

${ }^{17}$ We abstract from a non-negativity constraint on new projects.
} 
since depositors cannot observe the banks' risk choice and banks are protected by limited liability. The less equity a bank has, the higher the incentives for risk taking. Yet, since deposit insurance and the equity premium drive a wedge between the costs of deposits and equity, the banks' optimal capital structure comprises both equity and deposits, balancing the agency problem associated with deposits with the higher costs of equity. We will show that the equilibrium risk chosen by the banks is excessive, and that the interest rate influences the degree of its excessiveness.

We assume that there is a continuum of banks which behave competitively so that there is a representative bank (we therefore omit the bank's index in what follows). The bank is owned by the equity providers, and hence maximizes the expected discounted value of profits $^{18}$ using the household's stochastic discount factor. Every period, the bank optimally chooses its liability structure by raising deposits $d_{t}$ and equity $e_{t}$ from the respective funds. These resources are then invested into $o_{t}$ capital projects, purchased at price $Q_{t}$. When investing into capital projects, the bank chooses the risk characteristic $q_{t}$ of the technology applied by the capital producer. This risk choice is not observable for depositors. Each bank can only invest into one project and hence faces investment risk: ${ }^{19}$ with probability $q_{t}$ the bank receives a high payoff from the capital project; with probability $1-q_{t}$ the investment fails and yields only the liquidation value. Assuming a sufficiently low liquidation value $\theta$, a failed project implies the default of the bank. In this case, given limited liability, equity providers get nothing and depositors get the deposit insurance benefit. In case of success the bank can repay its investors: depositors receive their promised return $r_{d, t}$ and equity providers get the state-contingent return $r_{e, t+1}$.

\footnotetext{
${ }^{18}$ Profits in excess of the opportunity costs of equity.

${ }^{19}$ The assumption that the bank can only invest into one project and cannot diversify the project risk might sound stark. Yet three clarifications are in place: First, our set up is isomorphic to a model where the bank invests into an optimally diversified portfolio of investments but is too small to perfectly diversify its portfolio. The binary payoff is then to be interpreted as the portfolio's expected payoff conditional on default or repayment respectively. Second, if the bank could choose the degree of diversification (at stage 2 of the problem laid out below), but this choice were unobservable for the depositor, then the bank would have an incentive to choose minimal diversification in order to maximize the option value of default. We thank a referee for pointing this out. Third, we don't allow the bank to buy the government bond. Yet this assumption is innocuous: since the banks demand a higher return on investment than the households due to the equity premium, banks wouldn't purchase the safe asset even if they could.

${ }^{20}$ Our setup deviates from Modigliani-Miller in three dimensions. The unobservable risk choice at stage 2 , the (excess) equity premium $\xi$ and deposit insurance all imply that the capital structure is relevant for the funding costs of the bank. In the absence of the three aforementioned frictions, the irrelevance theorem would hold. Even then the safe interest rate $r_{d, t}$ would be smaller than the expected risky equity rate $E\left[r_{e, t+1}\right]$ to compensate for the risk involved. However the total funding costs would be independent of the capital structure. The excess equity premium $\xi$ hence is that part of the total equity premium, which cannot be explained by risk aversion.
} 
It is useful to think of the bank's problem as a recursive two-stage problem. At the second stage, the bank chooses the optimal risk level $q_{t}$ given a certain capital structure and a certain cost of deposits. At the first stage, the bank chooses the optimal capital structure, anticipating the implied solution for the second-stage problem. ${ }^{20}$ Note that not only the bank but also the bank's financiers anticipate the second-stage risk choice and price deposits and equity accordingly, which is understood by the bank.

Before we derive the solution for this recursive problem, we establish the bank's objective function. Per dollar of nominal funds raised in period $t$ the bank purchases $1 /\left(Q_{t} P_{t}\right)$ units of the capital project from the capital producer, choosing a certain riskiness $q_{t}$. If the project is successful it turns into $\left(\omega_{1}-\frac{\omega_{2}}{2} q_{t}\right) /\left(Q_{t} P_{t}\right)$ capital goods. In the next period $t+1$, the bank rents the capital to the firm, which pays the real rental rate $r_{k, t+1}$ per unit of capital. Furthermore the bank receives the depreciated capital, which becomes a capital project again, with a real value of $(1-\delta) Q_{t+1}$ per unit of capital. The bank's total nominal income, per dollar raised, conditional on success is therefore: $\left(\omega_{1}-\frac{\omega_{2}}{2} q_{t}\right) \frac{r_{k, t+1}+(1-\delta) Q_{t+1}}{Q_{t}} \frac{P_{t+1}}{P_{t}}$.

At the same time, the bank has to repay the deposit and equity providers. Using the equity ratio $k_{t}$, the total nominal repayment per dollar of funds due in $t+1$ in the event of success is $r_{e, t+1} k_{t}+r_{d, t}\left(1-k_{t}\right)$.

The bank maximizes the expected discounted value of excess profits, i.e. revenues minus funding costs, using the stochastic discount factor of the equity holders, i.e. the household. Given the success probability of $q_{t}{ }^{21}$ the bank's objective function is:

$$
\max _{q_{t}, k_{t}} \beta E\left[\frac{\Lambda_{t+1}}{\pi_{t+1}} q_{t}\left(\left(\omega_{1}-\frac{\omega_{2}}{2} q_{t}\right) \frac{r_{k, t+1}+(1-\delta) Q_{t+1}}{Q_{t}} \pi_{t+1}-r_{d, t}\left(1-k_{t}\right)-r_{e, t+1} k_{t}\right)\right] .
$$

Note that we did not multiply the per-unit profits by the quantity of investment. By doing so we anticipate the equilibrium condition that the bank, whose objective function is linear in the quantity of investment, needs to be indifferent about the quantity of investment. The quantity will be pinned down together with the return on capital by the bank's balance sheet equation $e_{t}+d_{t}=Q_{t} o_{t}$, the market clearing and zero-profit conditions.

\subsubsection{Simplified version of the bank model}

The bank's problem can be solved analytically, yet the expressions get fairly complex. Therefore we derive here the solution for $\psi=\theta=0$, that is without deposit insurance and with a liquidation value of 0 . This simplifies the expressions but the intuition remains the same. Allowing $\psi$ and $\theta$ to be nonzero on the other hand is

\footnotetext{
${ }^{21}$ Here we anticipate that the bank defaults in the event of a bad project outcome. See Section 2.4 .3
} 
necessary to bring the model closer to the data. The solution for the general case is discussed in Section 2.4.3.

To make notation more tractable we rewrite the bank's objective function (7) in real variables expressed in marginal utility units: ${ }^{22}$

$$
\omega_{1} q_{t} \tilde{r}_{l, t}-\frac{\omega_{2}}{2} q_{t}^{2} \tilde{r}_{l, t}-q_{t} \tilde{r}_{d, t}\left(1-k_{t}\right)-q_{t} \tilde{r}_{e, t} k_{t},
$$

For later use we rewrite the household's no-arbitrage conditions (1) and (2) combined with the definition of the funds' returns (3) and (4) as $\tilde{r}_{d, t}=\frac{\tilde{R}_{t}}{q_{t}}$ and $\tilde{r}_{e, t}=\frac{\tilde{R}_{t}+\tilde{\xi}_{t}}{q_{t}}$. We now solve the bank's problem recursively.At the second stage, the bank has already raised $e_{t}+d_{t}$ funds and now needs to choose the risk characteristic of the investment $q_{t}$, such that equity holders' utility is maximized. As already mentioned, we assume that the bank cannot write contracts conditional on $q_{t}$ with the depositors at stage one, since $q_{t}$ is not observable to them. Therefore, at the second stage the bank takes the deposit rate as given. Furthermore, since the capital structure is already determined, maximizing the excess profit coincides with maximizing the profit of equity holders. ${ }^{23}$ The bank's second stage problem is therefore (see Figure 1 for illustration):

$$
\max _{q_{t}} \omega_{1} q_{t} \tilde{r}_{l, t}-\frac{\omega_{2}}{2} q_{t}^{2} \tilde{r}_{l, t}-q_{t} \tilde{r}_{d, t}\left(1-k_{t}\right) .
$$

Deriving problem (9) with respect to $q_{t}$ yields the following first order condition:

$$
\hat{q}_{t}=\frac{\omega_{1} \tilde{r}_{l, t}-\tilde{r}_{d, t}\left(1-k_{t}\right)}{\omega_{2} \tilde{r}_{l, t}} .
$$

This condition defines the optimum, provided the solution is interior. From now on we shall always assume that solutions are interior, which of course implies certain restrictions on parameters. ${ }^{24}$

At the first stage, the bank chooses the capital structure $k_{t}$ to maximize excess profits, anticipating the $\hat{q}_{t}\left(k_{t}\right)$ that will be chosen at the second stage, and subject to the participation constraints (i.e. the funding supply schedules) for depositors and equity providers:

\footnotetext{
${ }^{22}$ That is, we use the following definitions: $\tilde{r}_{l, t}=E_{t}\left[\Lambda_{t+1}\left(\frac{r_{k, t+1}+(1-\delta) Q_{t+1}}{Q_{t}}\right)\right], \tilde{r}_{d, t}=$ $E_{t}\left[\Lambda_{t+1} \frac{r_{d, t}}{\pi_{t+1}}\right], \tilde{r}_{e, t}=E_{t}\left[\Lambda_{t+1} \frac{r_{e, t+1}}{\pi_{t+1}}\right], \tilde{R}_{t}=E_{t}\left[\Lambda_{t+1} \frac{R_{t}}{\pi_{t+1}}\right], \tilde{\xi}_{t}=E_{t}\left[\Lambda_{t+1} \xi_{t}\right]$.

${ }^{23}$ I.e. we could equivalently have the banker maximize expected profits net of the opportunity costs of equity: $\max _{q_{t}} \omega_{1} q_{t} \tilde{r}_{l, t}-\frac{\omega_{2}}{2} q_{t}^{2} \tilde{r}_{l, t}-q_{t} \tilde{r}_{d, t}\left(1-k_{t}\right)-q_{t} \tilde{r}_{e, t} k_{t} \quad$ s.t. $\tilde{r}_{e, t}=\frac{\tilde{R}_{t}+\tilde{\xi}_{t}}{q_{t}}$

${ }^{24} \mathrm{We}$ focus on interior solutions, since our objective is to explain both the risk and leverage choices of the bank, and to allow them to depend on the state of the economy. In the estimation we verify that the parameters are such as to allow for an interior solution of the bank's problem in the vicinity of the steady state.
} 


$$
\begin{gathered}
\max _{k_{t}} \hat{q}_{t} \omega_{1} \tilde{r}_{l, t}-\frac{\omega_{2}}{2} \tilde{r}_{l, t} \hat{q}_{t}^{2}-\hat{q}_{t} \tilde{r}_{d, t}\left(1-k_{t}\right)-\hat{q}_{t} \tilde{r}_{e, t} k_{t}, \\
\text { s.t. } \tilde{r}_{d, t}=\frac{\tilde{R}_{t}}{\hat{q}_{t}} \text { and } \quad \tilde{r}_{e, t}=\frac{\tilde{R}_{t}+\tilde{\xi}_{t}}{\hat{q}_{t}}
\end{gathered}
$$

This problem can be solved for $k_{t}$ as: ${ }^{25}$

$$
\hat{k}_{t} \equiv k_{t}\left(\tilde{r}_{l, t}\right)=1-\frac{\tilde{\xi}_{t}\left(\tilde{R}_{t}+\tilde{\xi}_{t}\right)\left(\omega_{1} \tilde{r}_{l, t}\right)^{2}}{\omega_{2} \tilde{R}_{t} \tilde{r}_{l, t}\left(\tilde{R}_{t}+2 \tilde{\xi}_{t}^{2}\right)} .
$$

Since there is a continuum of identical banks, each bank behaves competitively taking the return on investment $\tilde{r}_{l, t}$ as given, and there are no expected excess profits to be made. In the presence of uncertainty it is natural to focus on the case that banks make no excess profit in any future state of the world:

$$
\left(\omega_{1}-\frac{\omega_{2}}{2} q_{t-1}\right)\left(\frac{r_{k, t}+(1-\delta) Q_{t}}{Q_{t-1}}\right)-\frac{r_{d, t-1}}{\pi_{t}}\left(1-\hat{k}_{t-1}\right)-\frac{r_{e, t}}{\pi_{t}} \hat{k}_{t-1}=0
$$

Using the equity and deposit supply schedules and taking expectation over this equation we get:

$$
\hat{q}_{t} \omega_{1} \tilde{r}_{l, t}-\frac{\omega_{2}}{2} \tilde{r}_{l, t} \hat{q}_{t}^{2}-\hat{k}_{t} \tilde{\xi}_{t}-\tilde{R}_{t}=0
$$

Combining (14) with the optimality conditions (10) and (12), we can derive analytical expressions for the equity ratio $k_{t}$, riskiness choice $q_{t}$ (the last term in each row is an approximation under certainty equivalence and $R_{t}^{r} \equiv R_{t} / E_{t}\left[\pi_{t+1}\right]$ ):

$$
\begin{array}{rlr}
k_{t}= & \frac{\tilde{R}_{t}}{\tilde{R}_{t}+2 \tilde{\xi}_{t}} \approx & \frac{R_{t}^{r}}{R_{t}^{r}+2 \xi_{t}} \\
q_{t}= & \frac{\omega_{1}\left(\tilde{\xi}_{t}+\tilde{R}_{t}\right)}{\omega_{2}\left(2 \tilde{\xi}_{t}+\tilde{R}_{t}\right)} \approx & \frac{\omega_{1}\left(\xi_{t}+R_{t}^{r}\right)}{\omega_{2}\left(2 \xi_{t}+R_{t}^{r}\right)}
\end{array}
$$

\subsubsection{Properties of the banking sector equilibrium}

These results for the banking sector risk choice have five interesting implications that we first summarize in a proposition, before intuitively discussing them in turn.

Proposition 1: $\quad \operatorname{Be}\left[\tilde{r}_{l, t}, q_{t}, k_{t}\right]$ an equilibrium in the banking sector with interior bank choices under perfect competition. Denote the expected return on investment expressed in units of capital by $f\left(q_{t}\right) \equiv\left(\omega_{1}-\frac{\omega_{2}}{2} q_{t}\right) q_{t}$. Then:

Risk decreases in the real interest rate: $\frac{\partial q_{t}}{\partial \tilde{R}_{t}}>0$.

\footnotetext{
${ }^{25}$ Notice that we focus on the solution associated with the bigger of 2 roots for $q_{t}$. This solution is closer to the optimal choice of $q_{t}$, as discussed below.
} 
The equity ratio increases in the real interest rate: $\frac{\partial k_{t}}{\partial \tilde{R}_{t}}>0$.

Risk taking is excessive: $q_{t}<\operatorname{argmax} f\left(q_{t}\right)$.

The expected return on investment increases in the real interest rate: $\frac{\partial f\left(q_{t}\right)}{\partial \tilde{R}_{t}}>0$.

The expected return on investment is a concave function of the real interest rate $\frac{\partial^{2} f\left(q_{t}\right)}{\partial \tilde{R}_{t}^{2}}<0$.

The proof can be found in Appendix C. Figure 1 illustrates the properties 1, 3 and 4.

The first two results can be easily seen from equations (15) and (16). As the real risk-free rate $R_{t}^{r}$ decreases, the equity ratio $k_{t}$ falls as banks replace equity with deposits and the riskiness of the bank increases ( $q_{t}$ falls). ${ }^{26}$ The intuition behind this result is as follows: On the one hand, a lower risk-free rate decreases the rate of return on capital projects, reducing the benefits of safer investments,

Figure 1: The bank's risk choice: The solid line is the expected return of the investment as a function of the level of safety $q$ chosen. The dashed curve describes the return on equity, which is maximized at the second stage for given $r_{d}, r_{l}$ and $k$. It's maximum is marked by the black dot. A reduction in the real rate, through its effects on $(1-k) r_{d} / r_{l}$ shifts the dashed curve down-left (not shown), which leads to a lower choice of $q$ (gray dot).

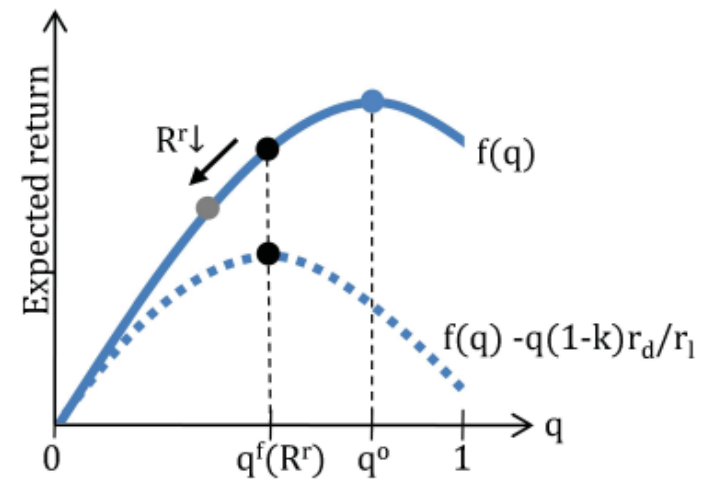

conditional on repayment. This induces the bank to adopt a riskier investment technology. On the other hand, the lower risk-free rate reduces the cost of funding, leaving more resources available to the bank's owners in case of repayment: this force contrasts with the first one, making safer investments more attractive. There is a third force: a lower risk-free interest rate means that the equity premium becomes relatively more important. As a result the bank shifts from equity to deposits, internalizing less the consequences of the risk decision and choosing a higher level of risk. The first and third effects dominate, and overall a decline in the real interest rate induces banks to choose more risk. Note that these two results

\footnotetext{
${ }^{26}$ At least under certainty equivalence or up to a first-order approximation, when the $\Lambda_{t+1}$ terms contained in the tilde variables cancel each other out.
} 
depend on the assumption that the (discounted) equity premium is independent of the (discounted) real interest rate. If we allowed the equity premium to be a function $\tilde{\xi}_{t}\left(\tilde{R}_{t}\right)$ of the real interest rate, the result would continue to hold under the condition that $\tilde{\xi}_{t}\left(\tilde{R}_{t}\right)>\tilde{\xi}_{t}^{\prime}\left(\tilde{R}_{t}\right) \tilde{R}_{t}$, which rules out proportionality. This mechanism provides a rationalization of the first stylized fact mentioned before: that a decline in the nominal interest rate ${ }^{27}$ causes an increase in bank risk-taking.

The third result implies that the bank's investment could have a higher expected return (in units of capital) if the bank chose a higher level of safety. In other words, risk taking is excessive, i.e. suboptimally high. This is due to the agency problem, which arises from limited liability and the lack of commitment/contractability of the banker regarding his risk choice. The importance of this friction can be assessed by comparing the solution of the imperfect markets bank model with the solution of the model without any frictions. The frictionless risk choice can be derived under any of the following alternative scenarios: either the equity premium is zero (which eliminates the cost disadvantage of equity and leads to $100 \%$ equity finance), or contracts are complete (which eliminates the agency problem and leads to $100 \%$ deposit finance), or liability is not limited (as before), or households invests directly into a diversified portfolio of capital projects (which eliminates the financial sector altogether). In a frictionless model $q_{t}$ is chosen to maximize the consumption value of the expected return: ${ }^{28}$

$$
\max _{q_{t}} \tilde{r}_{l, t}\left(\omega_{1}-\frac{\omega_{2}}{2} q_{t}\right) q_{t}
$$

and the optimal level of $q_{t}$ trivially is $q_{t}^{o}=\frac{\omega_{1}}{\omega_{2}}$. Comparing the frictionless risk choice $q_{t}^{o}$ and the choice given the friction $q_{t}^{f}$,

$$
q_{t}^{f}=q_{t}^{o} \frac{\tilde{\xi}_{t}+\tilde{R}_{t}}{2 \tilde{\xi}_{t}+\tilde{R}_{t}} \approx q_{t}^{o} \frac{\xi_{t}+R_{t}^{r}}{2 \xi_{t}+R_{t}^{r}},
$$

we observe that the agency friction drives a wedge between the frictionless risk level and the level that is actually chosen. This wedge has two important features. First, it is smaller than one, ${ }^{29}$ implying that under the agency problem the probability of repayment is too low, and hence banks choose excessive risk. Second, note that the wedge depends on $R_{t}^{r}$ and that the derivative of the first-order approximation of the wedge w.r.t. $R_{t}^{r}$ is positive. This implies that the wedge increases, i.e. risk taking gets more excessive, as the real interest rate falls. As we move further away from the optimal level of risk the expected return on investments necessarily falls, which is the fourth result above.

\footnotetext{
${ }^{27}$ In a monetary model, a cut in the nominal interest rate, the standard monetary policy tool, is followed by a decline in the real interest rate due to price stickiness.

${ }^{28}$ Note that in the model with full deposit insurance, also this insurance needs to be eliminated in order to obtain the efficient allocation.

${ }^{29}$ This is true under certainty equivalence, i.e. up to first-order approximation.
} 
But it is not only the bank risk choice that is suboptimal. The capital structure is chosen suboptimally too. If banks could commit to choose the optimal level of risk, they would not need any skin in the game. Hence they would avoid costly equity and would finance themselves entirely through deposits: $k_{t}^{o}=0$. Instead they choose $k_{t}^{f}=\frac{\tilde{R}_{t}}{\tilde{R}_{t}+2 \tilde{\xi}_{t}}$. The equity ratio resembles the two features of risk taking. First, there is excessive use of equity funding. Second, the equity ratio is increasing in $R_{t}^{r}$ up to a first-order approximation.

Both the risk and the capital structure choices have welfare implications. A marginal increase in $q_{t}$ means a more efficient risk choice, i.e. a higher expected return, and hence should be welfare improving, ceteris paribus. At the same time a marginal increase in $k_{t}$ implies, due to the equity premium, a higher markup in the intermediation process, which distorts the consumption savings choice and hence lowers welfare, ceteris paribus. Since both $q_{t}$ and $k_{t}$ are increasing functions of the real interest rate, this begs the question as to whether an increase in the real rate alleviates or intensifies the misallocation due to the banking friction. ${ }^{30}$ The answer to this question depends on the full set of general-equilibrium conditions. Given the estimated model, we will later numerically verify that the positive first effect dominates, i.e. an increase in $R_{t}^{r}$ has welfare improving consequences for the banking market. ${ }^{31}$ The existence of these opposing welfare effects motivates our optimal policy experiments in Section 4.

Finally, the last statement of the proposition implies that a mean-preserving increase in the variance of the real interest rate decreases the mean of the expected return on the bank's investment. This has implications for optimal monetary policy. As we discuss in detail later, the monetary authority cannot affect the nonstochastic steady state of the real rate, but it can influence its volatility. The policy maker therefore has an incentive to keep the real interest rate stable, at least as long as the opposing effect of the equity premium is negligible.

While Dell'Ariccia et al. (2014) derive results that resemble part 1 and 2 of this proposition, we go further by analyzing also the efficiency properties of risk taking in parts 3 to 5 . This is useful to understand potential policy implications, which we discuss below. Besides, in the next subsection we show that these results continue to hold for several extensions of the model. Moreover, our model makes a different assumption on timing, which is reflected in the way that $\omega_{2}$ appears in the objective function. Our setup does not just simplify the algebra, but, more importantly, it is also more natural in the context of a macro model, since it nests

\footnotetext{
${ }^{30}$ These two opposing forces are well known from the literature on bank capital regulation, where a rise in capital requirements hampers efficient intermediation but leads to a more stable banking sector.

${ }^{31}$ The dominance of the risk-taking effect is intuitive for two reasons. First, while risk taking entails a real cost, the equity premium just entails a wedge but no direct real costs. Second, as the real interest rate increases the equity premium becomes less important, so a more efficient allocation is intuitive.
} 
the RBC model as as special case. Finally note that those authors consider two settings, one where banks behave competitively and one where they have price setting power on the loan markets. While we focus on perfect competition for simplicity, it is reassuring that their results hold in both cases.

At the end of this subsection on the banks, let us briefly zoom out and consider the model as a whole. Note that the introduction of the financial sector adds two new variables to the standard New Keynesian model: The risk choice $q_{t}$ and the capital structure $k_{t}$. These choices imply two deviations from the New Keynesian model: While the capital structure choice introduces a time-varying spread between the return on capital and the return on investment, the risk choice implies that the efficiency of the capital production function varies with the interest rate. After substituting out all the financial sector variables in the system of equilibrium conditions, these two distortions show up as wedges that depend on the real interest rate in the household's Euler equation for physical capital and (in the latter case) the capital accumulation equation. Once any of the assumptions about financial frictions (incomplete contracts, limited liability, equity premium) are removed, the banks choices become optimal and constant and the model collapses to the New Keynesian model. ${ }^{32}$

\subsubsection{Full model with deposit insurance and liquidation value}

The simplified version of the bank's problem presented so far is useful to explain the basic mechanism. Yet deposit insurance and a non-zero liquidation value are important to improve the quantitative fit of our model to the data.

The assumptions made about deposit insurance and the liquidation value imply that depositors get the maximum of the amount covered by deposit insurance and the value of the capital recovered from a failed project. That means that their return in case of default is:

$$
\min \left(\frac{r_{d, t}}{\pi_{t+1}}, \max \left(\frac{r_{k, t+1}+(1-\delta) Q_{t+1}}{Q_{t}\left(1-k_{t}\right)} \frac{\theta}{1-k_{t}}, \frac{\psi}{1-k_{t}}\right)\right)
$$

To make deposit insurance meaningful we assume that the liquidation value $\theta$ is small enough such that $\frac{r_{k, t+1}+(1-\delta) Q_{t+1}}{Q_{t}\left(1-k_{t}\right)} \frac{\theta}{1-k_{t}}<\frac{\psi}{1-k_{t}}$, which eliminates the inner maximum. ${ }^{33}$ As the following lemma states, proven in Appendix C, the outer maximum is unambiguous in equilibrium. ${ }^{34}$

\footnotetext{
${ }^{32}$ Given adequate values for the parameters $\omega_{1}$ and $\omega_{2}$. Below we enforce this restriction.

${ }^{33}$ We later verify this assumption numerically at the steady state for the estimated model. In principle the fact that the return on capital is determined only one period later implies that we could have cases where this inequality is satisfied for some states of the world and violated for others. We abstract from this complication, since we later approximate our model locally around the steady state, which allows us to consider only small shocks.

${ }^{34}$ For this result we again abstract from the effect of uncertainty. See the previous footnote.
} 
Lemma: There can be no equilibrium such that the insurance cap is not binding, i.e. $\frac{r_{d, t}}{\pi_{t+1}}>\frac{\psi}{1-k_{t}}$.

Deposits therefore pay $\frac{\psi}{1-k_{t}}$ in case of default. Combining the nominal return on the deposit fund (3) with the household's no-arbitrage condition (1), and defining $\tilde{\psi}_{t}=E\left[\Lambda_{t+1}\right] \psi$, we can write the deposit supply schedule as

$$
q_{t} \tilde{r}_{d, t}+\left(1-q_{t}\right) \frac{\tilde{\psi}_{t}}{1-k_{t}}=\tilde{R}_{t}
$$

We assume that the deposit insurance scheme, which covers the gap between the insurance cap and the liquidation value for the depositors of failing banks, is financed through a variable tax on capital that is set ex post each period such that the insurance scheme breaks even. The return on loans $\tilde{r}_{l, t}$ can then be rewritten as:

$\tilde{r}_{l, t} \equiv E_{t}\left[\Lambda_{t+1} \frac{r_{k, t+1}+(1-\delta) Q_{t+1}-\tau_{t+1}}{Q_{t}}\right]$ where $\tau_{t}=\frac{Q_{t-1} \frac{1-q_{t-1}}{q_{t-1}}\left(\psi-\theta \frac{r_{k, t}+(1-\delta) Q_{t}}{Q_{t-1}}\right)}{\omega_{1}-\frac{\omega_{2}}{2} q_{t-1}}$

This way, the tax also perfectly offsets the distortion in the quantity of investment caused by the deposit insurance. Deposit insurance therefore influences only the funding decision of the bank and, through that, the risk choice. Hence, if $q_{t}$ was chosen optimally (or was simply a parameter) the deposit insurance would not have any effect.

The same procedure as outlined above can be applied to obtain closed-form solutions ${ }^{35}$ for the risk choice and the equity ratio. The solutions can be found in Appendix C. As stated below in proposition 2, the equilibrium characterizations in subsection 2.4 .2 remain valid. In particular, note that the deviation of the chosen risk (equity ratio) from the optimal level decreases (increases) in the real interest rate. Given our estimation, the risk effect dominates in terms of welfare implications. The intuition for the risk-taking channel is similar to before.

Deposit insurance makes deposits cheaper relative to equity. As a result, the bank demands more deposits and chooses a riskier investment portfolio. Deposit insurance furthermore strengthens the risk-taking channel, which is now affected not only by the importance of the equity premium relative to the real interest rate, but also by the importance of the deposit insurance cap relative to the real interest rate. On the other hand, the efficient risk level is not affected by deposit insurance.

\footnotetext{
${ }^{35}$ In this case, one needs to apply the adjusted deposit supply schedule (17) and to make sensible assumptions about the relative size of parameters and about the root when solving the zero-profit equation.
} 
The liquidation value, on the other hand, is irrelevant for the banks' and investors' choice, since it is assumed to be smaller than deposit insurance. Yet it eases the excessiveness of risk taking, since it increases the optimal level of risk: $q_{t}^{o}=\frac{\omega_{1}-\theta}{\omega_{2}}$.

An additional implication of our model is that both the expected loan profitability and, given the parameters estimated in Section 3, the loan risk premium fall as the real interest rate declines: a result which is in line with the respective findings of Ioannidou et al. (2014) and Buch et al. (2014).

Finally, we would like to point out that none of the results in proposition 1 is due to the functional form that we have assumed for the risk return trade-off. ${ }^{36}$ The statement holds even for a generic function $f\left(q_{t}\right)^{37}$ under relatively weak assumptions, some of which are sufficient but non necessary. For a proof and a discussion of these assumptions see Appendix C.

Proposition 2: $\quad$ Be $\left[\tilde{r}_{l, t}, q_{t}, k_{t}\right]$ an equilibrium in the banking sector with interior bank choices under perfect competition. Denote the expected return on investment - now inclusive of the liquidation value - expressed in units of capital by $\mathrm{f}\left(q_{t}\right) \equiv$ $\left(\omega_{1}-\frac{\omega_{2}}{2} q_{t}\right) q_{t}+\left(1-q_{t}\right) \theta=f\left(q_{t}\right)+\left(1-q_{t}\right) \theta$. Consider the 5 statements from proposition 1 , but replace $f\left(q_{t}\right)$ by $\mathrm{f}\left(q_{t}\right)$. Then:

Given this adjustment, all five statements of proposition 1 hold for the full bank model with deposit insurance and a small enough liquidation value as well.

Given this adjustment, statements (1)-(4) of proposition 1 hold for a generic conditional expected return function $f\left(q_{t}\right)$ with deposit insurance and a small enough liquidation value under the additional assumptions that $f\left(q_{t}\right)$ satisfies $f\left(q_{t}\right) \geq 0, f^{\prime \prime}\left(q_{t}\right)<0, f^{\prime \prime \prime}\left(q_{t}\right) \leq 0, f^{\prime \prime \prime \prime}\left(q_{t}\right) \leq 0$. Statement (5) holds if furthermore either the default probability is low relative to the parameters $\frac{q_{t}}{\left(1-q_{t}\right)} \tilde{\xi}_{t} \geq \tilde{R}_{t}-\tilde{\psi}_{t}$ or there is no deposit insurance $\tilde{\psi}_{t}=0$.

\subsection{Labor and goods sectors}

The labor and goods sectors feature monopolistic competition and nominal rigidities as Calvo (1983), which allow for a role for monetary policy. Since the modeling

\footnotetext{
${ }^{36}$ Proposition 1 is also robust to the alternative assumption that deposit insurance covers a fraction $\alpha$ of either the principal or the total value of outstanding deposits for low enough values of $\alpha$. However, for high values of $\alpha$ the solution of the bank's capital structure choice problem is no longer interior and the model predicts $\mathrm{k}=0$. I.e. the function $k(\alpha)$ features as jump from medium levels of $k$ to 0 at medium levels of $\alpha$. Due to this feature, these alternative models can not simultaneously match the empirical targets (for $\mathrm{q}, \mathrm{k}$ and the expected return), which we match in the calibration Section; we therefore focus on the specification in the text.

${ }^{37}$ Given that the recovery value $f\left(q_{t}\right)$ now describes the expected return conditional on success.
} 
of these sectors follows the canonical New Keynesian model, we discuss them briefly in Appendix B and refer to Smets and Wouters (2007) and Adjemian et al. (2008) for further details.

\subsection{Monetary and fiscal policy}

The central bank follows a nominal interest rate rule, targeting inflation and output deviations from the steady state. In addition, the fiscal authority finances a stochastic expenditure stream $g_{y} \bar{Y} \varepsilon_{t}^{G}$ through lump sum taxes.

\section{Dynamic implications of the risk-taking chan- nel in the estimated model}

We have embedded our risk-taking channel in a medium-scale model which closely resembles the non-linear version ${ }^{38}$ of Smets and Wouters (2007), and we next estimate the model parameters using Bayesian techniques. This serves two purposes. First, we want to assess whether the risk-taking channel improves the quantitative fit of the model, once other monetary and real frictions are taken into account. Second, Smets and Wouters (2007) provide a quantitative model that is able to replicate key empirical moments of the data, which are needed for the monetary policy evaluation we perform in Section 4.

\subsection{Model estimation}

We estimate a linearized version of the model with Bayesian techniques using eight US macroeconomic time series covering the period of the great moderation from 1984Q1 to 2007Q3. These include the seven series used by Smets and Wouters (2007), i.e. the federal funds rate, the log of hours worked, inflation and the growth rates in the real hourly wage and in per-capita real GDP, real consumption, and real investment. To identify the banking sector parameters we add a series of the banking sector equity ratio, which we construct from aggregate bank balance-sheet data provided by the FDIC. For a full description of the data we refer to Appendix A and to the supplementary material of Smets and Wouters (2007). The observation equations, linking the observed time series to the variables in the model, as well as the prior specifications and other details regarding the estimation can be found in Appendix B. While the priors of the non-bank parameters follow Smets

\footnotetext{
${ }^{38}$ Our model deviates from Smets and Wouters (2007) only to the extent that we abstract (for simplicity) from capital utilization, shown by the authors to be of secondary importance once wage stickiness is taken into account, and growth. We also use internal instead of external habits to avoid another source of inefficiency. Furthermore, since we add a time series for the estimation, we introduce a time preference shock and a bank equity premium shock instead of their risk premium shock.
} 
and Wouters (2007), the priors for the banking sector parameters are motivated by historical averages and external estimates for the US. Note that instead of forming priors directly about $\omega_{2}$ (risk return trade-off) and $\psi$ (deposit insurance), we rewrite these parameters as functions of the steady-state equity ratio $\bar{k}$ and default rate $\bar{q}$. The prior mean of the steady-state equity premium $\xi$ is centered around an annualized value of $6 \%$, in line with the empirical estimates of Mehra and Prescott (1985), while the prior distribution for $\bar{k}$ is diffuse and centered around the historic mean of $12 \%$. The prior for the liquidation value $\theta$ is set such that it is contained between 0.3 and 0.7 with a $95 \%$ probability, in line with the evidence provided by Altman et al. (2003). The success rate $\bar{q}$ is not well identified and is therefore fixed to 0.99 , which implies an annual default rate of $4 \%$, roughly in line with the historical average of delinquency rates on US business loans. Sensitivity tests have moreover shown that this parameter is only of small quantitative relevance. ${ }^{39}$ Lastly, we normalize the units of capital versus final goods by setting $\omega_{1}$ (return on the risky asset) such that one unit of final good is expected to produce one unit of capital good in steady state.

Table 4 in Appendix B summarizes the posterior parameter values, which are broadly in line with existing empirical estimates for the US. The key banking sector parameters that determine the importance of the risk-taking channel are well identified by the data. The steady-state equity ratio has a tight posterior around $12 \%$, the posterior mean of the equity premium is around an annualized value of $9 \%$, and the liquidation value is about $74 \%{ }^{40}$ For the following quantitative analysis we set the parameters to their posterior means.

\footnotetext{
${ }^{39}$ In particular, the implications for optimal monetary policy behavior are very robust to the value of the steady state default rate. What matters is the importance of the channel over the business cycle, determined predominantly by the liquidation value and the scope of deposit insurance.

${ }^{40}$ The implied mean value for deposit insurance cap $\psi$ of about $88 \%$ implies that $99 \%$ of deposits are insured in steady state. Demirgüç-Kunt et al. (2005) report that the explicit deposit insurance scheme in the US is estimated to cover between $60 \%$ and $65 \%$ of deposits. The divergence can be interpreted as implicit deposit guarantees resulting from the expectation of bailouts. The implied mean values of $\omega_{1}(1.13)$ and $\omega_{2}(0.2561)$ yield a corner solution for $q^{\text {opt }}$ at 1 .
} 
Figure 2: Monetary policy shock in the bank and benchmark models: dynamic responses in the bank model (solid red lines) and in the benchmark model (dashed blue lines) to an expansionary monetary policy shock, at the mean of the posterior distribution. Shaded areas denote the highest posterior density interval at $90 \%$ for the bank model impulse responses, and the black line the steady-state level. Inflation and interest rates are quarter-on-quarter rates.
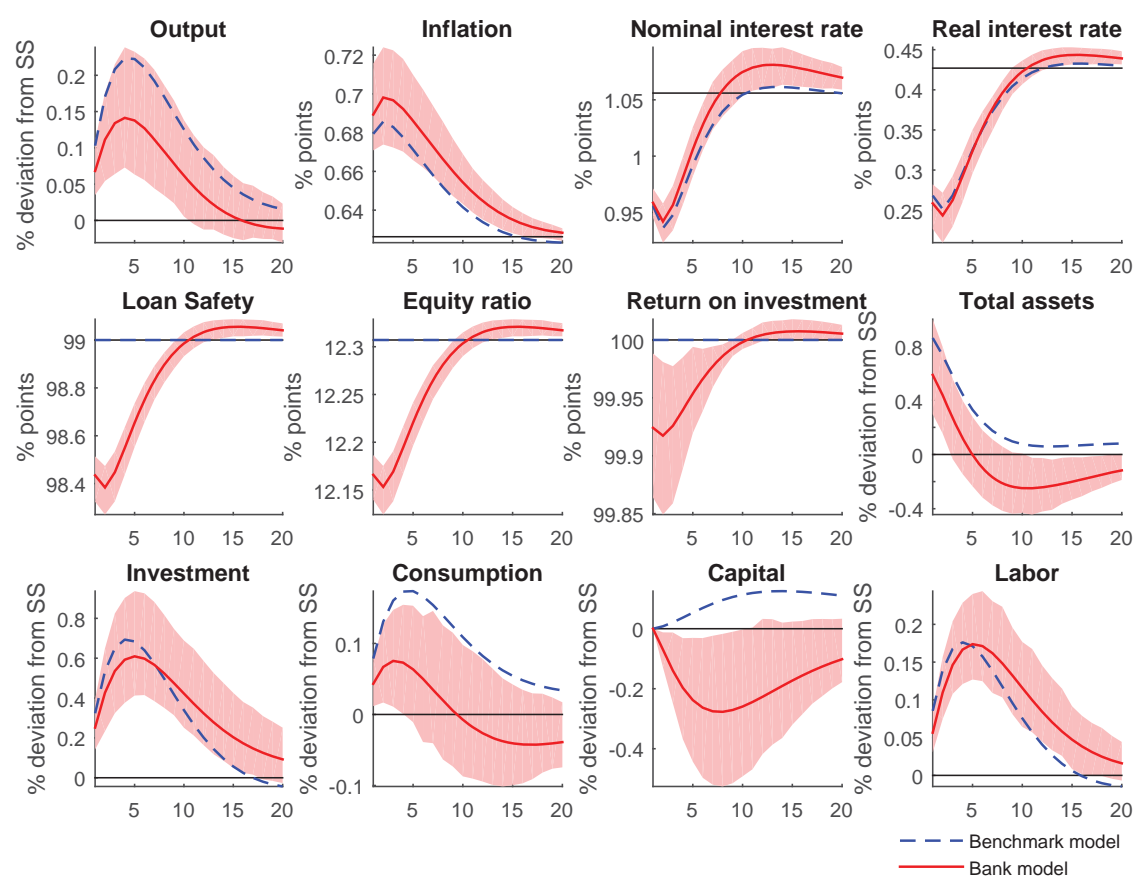

\subsection{Dynamic implications of excessive risk taking}

To illustrate the dynamic effects of the risk-taking channel, we assess how the propagation of monetary policy shocks is affected by the risk-taking channel. For this purpose, we compare the impulse responses of two models: with banking frictions (henceforth bank model), and without banking frictions. To enable the dynamic comparison, we equalize the steady states of the two economies. In particular, we alter the model without financial frictions by treating the risk choice $q_{t}$ and the equity ratio $k_{t}$ as fixed parameters, which we set to the steady-state values of the bank model. This model, henceforth benchmark model, has the same steady state as the bank model and corresponds to a standard New Keynesian model with a small markup in capital markets.

In Figure 2 we compare the dynamic responses in the bank model (solid red lines) and in the benchmark model (dashed blue lines) to an expansionary monetary policy shock. A monetary policy expansion triggers a set of standard reactions, which are evident in the benchmark model. An unexpected fall in the nominal risk-free rate causes a drop in the real interest rate, since prices are sticky. Consequently, consumption is shifted forward, firms that can adjust the price do so, causing an increase in inflation, while the remaining firms increase production. The risk-taking channel adds two further elements, as both the risk level and the 
capital structure chosen by the bank respond to the real interest rate movement. On impact, the drop in the real interest rate cause banks to replace equity with deposits, since the relative cost advantage of deposits increases. Consequently, banks have less skin in the game and hence take more risk (lower loan safety). The risk choice therefore moves further away from the optimal level, and the expected return on aggregate investment $f\left(q_{t}\right)$ drops. ${ }^{41}$ To maintain the same path of capital as in the benchmark case, households would have to invest more and consume less. Yet this would not be optimal because of consumption smoothing and because of the lower expected return on investment. Therefore, investment rises by less than what would be needed to compensate the loss in investment efficiency, which makes the capital stock decline considerably. Overall, agents are worse off (in terms of welfare) in the bank model than in the benchmark economy.

\subsection{Evaluating the fit of the estimated model}

Comparing our bank model to the benchmark Smets and Wouters (2007)-type model, we find that the bank model does a better job at explaining the 7 nonfinancial variables. ${ }^{42}$ In particular, the posterior odds ratio of $\exp (2.86)$ can be interpreted as providing 'positive' evidence in favor of the bank model, according to Jeffreys (1961) and Kass and Raftery (1995). To evaluate the plausibility of the strength of the proposed channel, we furthermore estimate a meta-model that nests both the benchmark and the bank model. This meta-model is characterized by the auxiliary parameter $\Gamma$, which defines the weight on each of the two models. ${ }^{43}$ Using a flat prior from 0 to 1 , we find that the posterior mean for $\Gamma$ lies at the corner at 0 , implying that the data rejects the benchmark model in favor of the risk-taking channel. ${ }^{44}$

A close examination of the role of the investment efficiency shock in the two estimated models provides some intuition for why the risk-taking channel improves the fit of the model. In particular, we find that the introduction of the banking frictions reduces the forecast error variance of output by a third, while the variance decomposition share of the investment shock drops from around 49 percent

\footnotetext{
${ }^{41}$ Note that the decline in the equity ratio diminishes the distortion due to the equity premium, which reduces the cost of capital. Yet this effect is tiny relative to the increase in the cost of capital due to lower investment efficiency.

${ }^{42}$ Recall that the Smets and Wouters (2007)-type model is obtained by turning off the banking sector frictions. Hence bank leverage is no longer defined. For the comparison we therefore estimate the two versions of the model (with and without the banking frictions) using only the seven macro aggregates used by Smets and Wouters (2007), and calibrate the banking parameters in the bank model to the posterior mean from our main estimation (Table 4).

${ }^{43}$ To set up this meta-model, we replace the equations for $k_{t}$ and $q_{t}$ in the bank model with: $k_{t}=\Gamma k_{t}^{\text {benchmark }}+(1-\Gamma) k_{t}^{\text {bank }}$ and $q_{t}=\Gamma q_{t}^{\text {benchmark }}(1-\Gamma) q_{t}^{\text {bank }}$, where $k_{t}^{x}$ corresponds to the RHS of the corresponding equation from the $x$ model. Again, this estimation is run using the 7 non-financial time series with fixed banking sector parameters.

${ }^{44}$ Note that this result is robust to removing the bounds of the prior.
} 
(estimated benchmark model) to 34 percent (estimated bank model) for horizons between 3 and 8 quarters. This relates to the argument of Justiniano et al. (2011), who find that the major role of this shock in explaining GDP volatility in the canonical medium-scaled Smets and Wouters (2007) model could be a spurious result that captures unmodeled financial frictions. In reducing the importance of this shock, the risk-taking channel seems to be capable of capturing at least some of this missing mechanism. This is intuitive because both the investment shock $\varepsilon_{t}^{I}$ and the expected return on the banks' investment $\mathrm{f}\left(q_{t}\right)=q_{t}\left(\omega_{1}-\frac{\omega_{2}}{2} q_{t}\right)+\left(1-q_{t}\right) \theta$ enter the capital accumulation equation multiplicatively:

$$
K_{t}=\left[\varepsilon_{t}^{I}\left(1-S\left(i_{t} / i_{t-1}\right)\right) i_{t}+(1-\delta) K_{t-1}\right]\left[q_{t}\left(\omega_{1}-\frac{\omega_{2}}{2} q_{t}\right)+\left(1-q_{t}\right) \theta\right] .
$$

Yet the two are not perfectly isomorphic, since the shock affects only net investment, while the expected return on investment affects gross investment. Moreover, the path of $\varepsilon_{t}^{I}$ backed out from the estimated benchmark model is strongly correlated with the path of the return on investment in the estimated bank model. ${ }^{45}$

To evaluate the fit with respect to financial variables we look at two statistics that were not targeted by the estimation. First, we compare the model-implied series for the risk variable $q_{t}$ with a survey-based proxy for bank risk taking. The latter is a weighted average ${ }^{46}$ of the internal risk rating assigned by banks to newly issued loans, provided by the US Terms of Business Lending Survey, and inverted so as to match the definition of $q_{t}$ in the model. Figure 3 shows that the model implies a cyclical pattern of risk that is roughly in line with the survey measure (the correlation is 60 percent). Second, the responses in Figure 2 also show that, conditional on the monetary policy shock, leverage (the inverse of the equity ratio $k_{t}$ ) is pro-cyclical with respect to the size of the bank balance sheet $e_{t}+d_{t}$. Conditional on the full set of shocks, we find a correlation of 43 percent which is in line with the evidence for US data provided by Adrian and Shin (2014), and distinguishes our model from canonical financial accelerator models that build on Bernanke et al. (1999). ${ }^{47}$

Overall, these findings suggest that the inclusion of the risk-taking channel improves the fit of nonfinancial data, while at the same time matching two key characteristics of aggregate banking sector data.

\footnotetext{
${ }^{45}$ For this exercise we use the same specification as for the likelihood comparison. Notice that the specification of our model is not exactly the same as Smets and Wouters (2007) and Justiniano et al. (2011) since we have abstracted from capital utilization and use internal rather than external habits. This means that the numbers are not directly comparable.

${ }^{46}$ For a detailed discussion about this variable we refer to Appendix D.

${ }^{47}$ See, for instance, the discussion in Adrian et al. (2015).
} 
Figure 3: Risk taking in the model and in the data: The Figure compares the value of loan safety $q_{t}$ implied by the estimated model (in particular we plot the mean of the series posterior distribution) with a survey-based index of loan safety computed from the US Terms of Business Lending Survey. For a more detailed discussion see text and Appendix D.

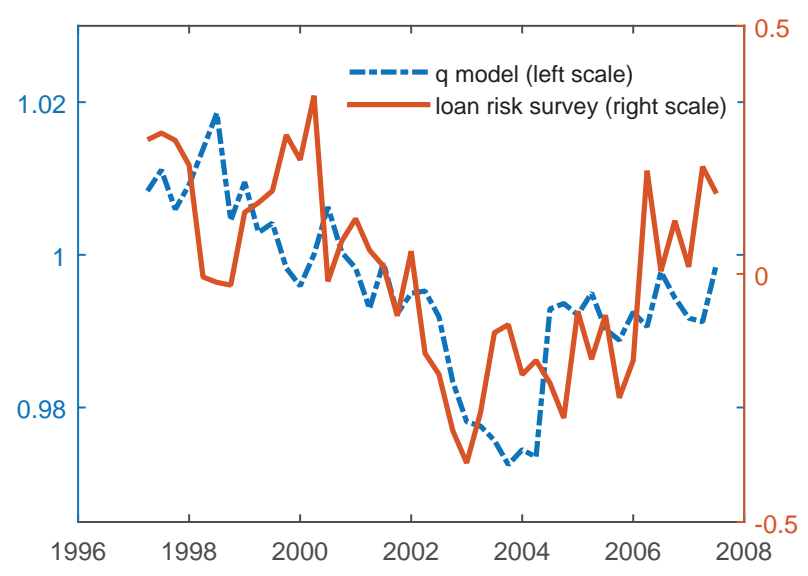

\section{Monetary policy with the risk-taking channel}

Optimal monetary policy in the benchmark Smets and Wouters (2007)-type model is well understood: it generally aims at mitigating the effect of coexisting nominal frictions (price and wage stickiness) and real frictions (monopolistic competition in goods and labor markets). The effect of price stickiness can be avoided by keeping price inflation stable. This way price dispersion and the productive inefficiencies associated with it are eliminated. While wage stickiness and the real frictions provide a motive to deviate from strict price inflation stabilization, their effect is typically quantitatively small and it is therefore, as Woodford (2004) puts it, "not a bad first approximation to say that the goal of monetary policy should be price stability". This goal is easy to implement with a simple Taylor rule that attaches a major weight to inflation.

The financial sector modeled in this paper adds another real friction: inefficient risk taking. As we have shown in the two propositions in Section 2.4, the intensity of this distortion depends on the real interest rate: Increases in the latter lower risk taking towards its efficient level, thereby increasing the aggregate efficiency of the capital production technology. Furthermore, we have shown that the efficiency of risk taking $\mathrm{f}\left(q_{t}\right)$ is concave in the real interest rate. This statement has two implications. First, an increase in the mean of the real rate improves the average efficiency of the risk choice $\mathrm{f}\left(q_{t}\right)$. Second, a mean-preserving spread of the real rate reduces the average expected return on investments $\mathrm{f}\left(q_{t}\right)$.

What does this new friction imply for the monetary policy maker? Due to monetary neutrality in the long run, monetary policy cannot affect the long run level (the mean, to first order) of the real rate and hence the long run effect of this 
friction. However, due to price stickiness, by setting the nominal rate, the policy maker can affect the volatility of the real rate. This in turn affects the average level of the efficiency of the risk choice $\mathrm{f}\left(q_{t}\right)$ due to the concavity of $\mathrm{f}\left(q_{t}\right)$ in the real rate. Therefore the risk-taking channel provides a motive for keeping the real interest rate constant. Just as price stickiness calls for a reduction of the volatility of inflation, risk taking calls for a reduction of the volatility of the real rate.

Yet this new objective conflicts with the inflation stabilization objective resulting from nominal rigidities, since the latter call for aggressive movements in both the nominal and the real rate. The risk-taking channel therefore introduces a new monetary policy trade-off between inflation and real interest rate stabilization. As a result, the central bank should accept higher inflation volatility in order to reduce the distortion stemming from risk taking.

But is this new trade-off actually quantitatively significant for monetary policy? Given that previous studies have found the optimality of inflation stabilization to be quantitatively robust to the introduction of financial frictions (e.g. De Fiore and Tristani (2013) and Bernanke and Gertler (2001)), the answer to this question is not trivial. To answer this question we determine optimal simple implementable monetary policy rules in both the bank and benchmark models, and compare their performance in the bank economy. This comparison has an interesting interpretation. Suppose that the actual economy features the risk-taking channel (the bank model), but that the central bank is unaware of this channel and believes that risk cannot be influenced by the interest rate. The central bank would then implement optimal policy based on a wrong model (the benchmark model). Our comparison then answers the question of how important it is to understand the risk-taking channel, in terms of optimal policy and welfare. For this experiment we use the parameters estimated for the bank model both for the bank and benchmark economy. ${ }^{48}$ This allows us to isolate the dynamic differences of the two models. However, taking this interpretation literally, it might seem more natural to assume that the central bank determines her policy based on an estimation of the benchmark model. As Appendix D shows, the findings we report below are robust (slightly stronger) to this alternative scenario.

Notice that in this paper we consider a central bank that has no policy tools besides the interest rate; in particular it does not regulate the equity ratio. This has implications for our positive and our normative analysis. Regarding the former, we believe that abstracting from regulation is acceptable for several reasons. First, the regulatory framework in place during most of the estimation period (Basel I), seems

\footnotetext{
${ }^{48}$ I.e. we keep all parameters fixed for this comparison, apart from the banking sector which we switch on or off.
} 
to have been too lax to be considered effectively binding. ${ }^{49}$ Second, a large share of the financial system, from off-balance-sheet vehicles to investment banks, is not covered by regulation. Third, our model predicts a negative correlation between the equity ratio and the interest rate, which in turn is negatively correlated to the cycle. Hence, with countercyclical regulation, which is endorsed in the latest regulatory framework (Basel III), the regulatory capital ratio would move in a similar way as postulated by our model.

Analyzing the normative implications of the risk-taking channel for regulation, though interesting, goes beyond the scope of the present paper. ${ }^{50}$ Arguably such an attempt might require a more complex model, where regulators can control bank risk choices only to a limited extent, and where a role for monetary policy remains. Instead we focus on what the monetary policy maker can do about risk taking in the (realistic) case that the problem persists despite regulation. Using monetary policy to address shortcomings of "imperfect" regulation is advocated in a similar context e.g. by Stein (2013) and Bean et al. (2015).

\subsection{The central bank problem}

We follow Schmitt-Grohe and Uribe (2007) and characterize optimal monetary policy as the policy rule that maximizes welfare among the class of simple, implementable interest-rate feedback rules ${ }^{51}$ given by

$$
R_{t}-\bar{R}=\phi_{\pi} \hat{\pi}_{t+s}+\phi_{y} \hat{y}_{t+s}+\phi_{k} \hat{k}_{t+s}+\rho\left(R_{t-1}-\bar{R}\right)
$$

where the hat symbol denotes percentage deviations from the steady state (in case of $s>0$ in expectations), and the index $s$ allows for forward- or contemporaneous-

\footnotetext{
${ }^{49}$ According to the Basel I accord implemented in 1992, banks were required to hold capital equal to $8 \%$ of their risk-weighted assets. Mortgages and mortgage-backed security held a very low risk weight, arguably leading banks to acquire more of these assets in order to reduce their total risk-weighted assets and through that, bank requirements. The share of risk-weighted assets to total bank assets fell in fact from $70 \%$ in 1992 to about $35 \%$ in the years preceding the crisis (Slovik (2012)), implying that regulation was based only on a small fraction of banks' balance sheets. As the 2008 financial crisis shows, the risks tackled by regulation did not coincide with the actual risks to which the financial sector was ultimately exposed.

${ }^{50}$ For an analysis of macroprudential regulation in an economy with bank risk-taking see for example Collard et al. (2012).

${ }^{51}$ The implementability criterion requires uniqueness of the rational expectations equilibrium, while simplicity requires the interest rate to be a function of readily observable variables. For a complete discussion, see Schmitt-Grohe and Uribe (2007). Notice that we drop their second requirement for implementability, which is that an implementable rule must avoid regular zero lower bound violations.
} 
looking rules (respectively by setting $s=1$ or $s=0$ ). ${ }^{52}$ The policy rule specification (18) is chosen for its generality, as it encompasses both standard Taylor-type rules (setting $\phi_{k}=0$ ), and the possibility that the central bank reacts to banking sector leverage, the inverse of the equity ratio $k\left(\phi_{k} \neq 0\right)$. A fall in the equity ratio implies that banks increase their debt financing, i.e. they increase leverage. As a consequence, banks internalize less the downside risk of their investments, and choose loans with a higher default probability. Hence, a fall in the equity ratio signals an increase in risk taking, to which the central bank may want to respond by increasing the interest rate. We choose not to let the interest rate depend on risk taking directly, because the latter is not a readily observable variable. We furthermore impose that the inertia parameter $\rho$ has to be non-negative. Since we are interested in the effect of systematic monetary policy, we switch off the monetary policy shock for this experiment.

The welfare criterion that defines the optimal parameter combination for rule (18) is the household's conditional lifetime utility. ${ }^{53}$ In order to compare welfare levels we define the measure $\Omega$ as the fraction of the consumption stream that a household would need to receive as a transfer under the suboptimal rule to be equally well off as under the optimal rule. If $o$ denotes the optimal rule and $s$ another suboptimal rule, this fraction $\Omega$ is implicitly defined by the equation:

$$
V^{o}=E_{0} \sum_{t=0}^{\infty} \beta^{t} \varepsilon_{t}^{B} u\left((1+\Omega) c_{t}^{s}, L_{t}^{s}\right)
$$

\footnotetext{
${ }^{52}$ Alternative ways to get at optimal monetary policy include linear-quadratic approximation of the welfare function and numerical determination of Ramsey optimal policy. Following a large literature, we focus on optimal simple rules instead of Ramsey policies here, because they seem to be more realistically implementable and they are generally found to be more robust than Ramsey optimal policies to the model misspecification (compare e.g. Levin et al. (1999) or Taylor (2007)). We refrain from linear-quadratic approximation because it is difficult to obtain useful results in medium scale models with capital.

${ }^{53}$ This measure, which is conditional on the economy being in steady state, is common in the literature.
} 
Table 1: Optimal simple rules: The first (second) column describes the timing (restrictions) of the policy rule. The last row corresponds to a rule where only $\phi_{k}$ can be chosen and the other parameters are fixed to the optimized benchmark values. $V$ is the welfare level associated with each policy in the bank model. $\Omega$ is the welfare cost (in $\%$ of the consumption stream) associated with implementing in the bank model the optimal policy rule of the benchmark model. For the benchmark model the restriction $\phi_{k}=0$ is irrelevant, since the equity ratio is constant. Italics indicate restricted parameters.

\begin{tabular}{cc|ccc|cccccc}
\hline & & \multicolumn{6}{|c|}{ benchmark model } & \multicolumn{7}{c}{ bank model } \\
$s$ & rule & $\rho$ & $\phi_{\pi_{t+s}}$ & $\phi_{y_{t+s}}$ & $\rho$ & $\phi_{\pi_{t+s}}$ & $\phi_{y_{t+s}}$ & $\phi_{k_{t}}$ & $V$ & $\Omega$ \\
\hline 0 & $\phi_{k}, \rho=0$ & 0 & 7.100 & 0.115 & 0 & 3.080 & 0.126 & 0 & -185.321 & 0.476 \\
0 & $\phi_{k}=0$ & 0.000 & 7.100 & 0.115 & 1.059 & 0.510 & 0.005 & 0 & -184.750 & 0.898 \\
0 & $\rho=0$ & 0 & 7.100 & 0.115 & 0 & 2.637 & 0.097 & 0.027 & -185.314 & 0.481 \\
1 & $\phi_{k}, \rho=0$ & 0 & 17.222 & 0.148 & 0 & 4.294 & 0.172 & 0 & -185.209 & 0.687 \\
1 & $\phi_{k}=0$ & 0.236 & 12.084 & 0.124 & 1.114 & 0.072 & 0.074 & 0 & -184.656 & 0.813 \\
0 & choose $\phi_{k}$ & 0.000 & 7.100 & 0.115 & 0 & 7.100 & 0.115 & -0.177 & -185.438 & 0.389 \\
\hline
\end{tabular}

\section{$4.2 \quad$ Findings}

Using the welfare criterion just described, we numerically determine the coefficients of the optimal simple implementable rules in the benchmark and in the bank model, using second-order approximations around the non-stochastic steady state. The first five rows of Table 1 report the optimal coefficients for five different specifications of the monetary policy rule: contemporaneous and forward-looking, without inertia and with optimal inertia, without and with a reaction to current leverage. The coefficients of the optimal rules generally vary greatly between the two models. A set of results which are robust across policy rule and estimation ${ }^{54}$ specifications, are worth noticing.

First, the optimal coefficients on inflation deviations are smaller in the bank model compared to the benchmark model. Given that the optimal output coefficient is close to zero, the optimal rule is hence closer to a stable real interest rate rule in the bank model than in the benchmark model. Furthermore, if the central bank can optimize over its smoothing parameter, then full interest rate smoothing is optimal in the bank model. Table 2, which displays the changes in the mean and volatility of key variables in switching from the benchmark optimal rule to the bank optimal rule in the bank model, helps to understand the rationale behind these results. By responding less aggressively to inflation and by smoothing the nominal interest rate, the central bank limits fluctuations in the real interest rate. The lower volatility of $R_{t}^{r}$ translates into a higher average return on investment

\footnotetext{
${ }^{54}$ We have experimented with different estimation samples and calibrated parameter values. While the optimized parameters and transfers slightly change, the qualitative results discussed in the text are very robust.
} 
$\mathrm{f}\left(q_{t}\right)$ due to the concavity of this function in $R_{t}^{r} .{ }^{55}$ This higher average return on investment comes at the cost of a significantly higher inflation volatility. Hence, the new trade-off between inflation and real rate stabilization implies a significant deviation from inflation stabilization. ${ }^{56}$

To understand how different the equilibria associated to the two optimal rules are, and therefore how important it is for the central bank to take the risk-taking channel into account, we compute the cost $\Omega$ of applying the rule that is optimal for the benchmark model in the bank model. These costs, expressed in $\%$ of the lifetime consumption stream, are reported in the last column of Table 1. Though the costs vary greatly across policy specifications, they are always significant. For the best-performing policy (fifth row of Table 1), the costs of applying the benchmark policy in the bank model are around $0.81 \%$ of the lifetime consumption stream. Unlike the financial frictions analyzed by De Fiore and Tristani (2013)

Table 2: Differences in moments associated with the optimal simple rules in the benchmark and in the bank model: This Table shows the \% differences in the mean and standard deviation associated with applying the different optimal rules in the bank model. The first entry, for example, indicates that under the optimal bank policy rule average risk would be $0.15 \%$ lower than if the rule optimal for the benchmark model had been applied.

\begin{tabular}{cc|cccccc|ccccc}
\hline & & \multicolumn{9}{|c|}{ mean } & \multicolumn{5}{c}{ standard deviation } \\
$s$ & rule & $q$ & $R^{r}$ & $\pi$ & $y$ & $c$ & $f(q)$ & $q$ & $R^{r}$ & $\pi$ & $y$ & $c$ \\
\hline 0 & $\phi_{k}, \rho=0$ & 0.151 & 0.002 & -0.051 & 0.311 & 0.499 & 0.045 & -43.880 & -47.975 & 52.470 & -0.843 & -4.108 \\
0 & $\phi_{k}=0$ & 0.214 & 0.007 & -0.038 & 0.439 & 0.701 & 0.061 & -67.949 & -77.760 & 64.393 & -9.545 & -9.566 \\
0 & $\rho=0$ & 0.152 & 0.003 & -0.015 & 0.323 & 0.506 & 0.045 & -41.666 & -47.248 & 53.194 & -0.773 & -3.800 \\
1 & $\phi_{k}, \rho=0$ & 0.194 & 0.011 & -0.037 & 0.413 & 0.652 & 0.062 & -50.536 & -55.417 & 57.719 & -2.781 & -6.906 \\
1 & $\phi_{k}=0$ & 0.195 & 0.004 & -0.054 & 0.458 & 0.724 & 0.057 & -65.839 & -76.3112 & 71.906 & -10.373 & -11.737 \\
0 & choose $\phi_{k}$ & 0.130 & 0.001 & -0.070 & 0.244 & 0.417 & 0.042 & -41.691 & -41.948 & 31.838 & 3.323 & -0.345 \\
\hline
\end{tabular}

and Bernanke and Gertler (2001), the risk-taking channel therefore has implications for monetary policy that are important both in terms of the prescribed policy and the cost of deviating from it.

Second, including an explicit response to banking sector leverage, in addition to inflation and output, improves welfare only marginally (compare the last column of the first and third row of Table 1). Recall that leverage depends on both the

\footnotetext{
${ }^{55}$ Note that the slight increase in $R_{t}^{r}$ accounts only for a marginal fraction of the increase in $f\left(q_{t}\right)$.

${ }^{56}$ One may additionally be interested to know how the OSR in the benchmark model compares to the OSR in the bank model in terms of means and volatilities. To this end, Table 7 in Appendix D reproduces the comparison of means and standard deviations in Table 2, but instead of comparing how different policy rules perform in the bank model it compares the optimal simple rules in each corresponding model. As a comparison of tables 2 and 7 reveals, virtually all of the differences in means and volatilities documented in the Table in the Appendix are due to the different policy rules, and not due to the differeces in the financial sector. I.e. the rule optimal in the benchmark model delivers higher real rate volatility and lower inflation volatility both in both in the benchmark model as well as in the bank model, compared to the bank model with its optimized simple rule.
} 
nominal interest rate and expected inflation. By setting the nominal rate optimally as a function of current inflation, the central bank can already steer risk taking, to the extent that current and expected future inflation are highly correlated. The fact that this correlation is not perfect, and that our approximation allows for nonlinearities, accounts for the small improvement in welfare obtained by allowing a response to leverage in the policy function. To further illustrate this point, in the last row we fix the coefficients of current inflation and output to the values which are optimal in the benchmark economy, and allow the central bank to respond optimally only to leverage. In this case, it is optimal to strongly raise the interest rate in response to higher leverage (lower equity ratio k). Thereby the central bank again stabilizes the real interest rate and does not do much worse in terms of welfare than when the responses to inflation and output are chosen optimally (compare the last column of the third and sixth row of Tables 1 and 2).

\section{Conclusion}

Recent empirical evidence suggests that monetary policy can influence bank risktaking behaviour. However, the economic relevance of this connection and its implications for monetary policy are still unclear. We address these questions by developing and estimating a quantitative general-equilibrium model where interest rates affect bank risk taking.

In the model, all savings are intermediated by banks, which make risky investments. Low levels of the risk-free interest rate induce banks to make riskier and therefore less efficient investments. At the core of this mechanism is an agency problem between depositors and equity providers: The latter choose the level of risk but are protected by limited liability. The response of risk taking to interest rates alters the dynamics in the model. To validate the risk-taking channel and gauge its importance, we estimate the model with Bayesian methods for the US. We find that this new channel not only improves the fit of the model but also predicts a path for risk taking that is in line with survey evidence.

We use the model to derive both analytical and quantitative implications for monetary policy. We show analytically that the risk-taking channel implies a motive for real interest rate stabilization. Since this motive conflicts with the inflation stabilization objective, it generates a new trade-off for the central bank. We then use the estimated model to analyze the quantitative importance of this new trade-off. We find that the risk-taking channel calls for significant deviations from inflation stabilization. The policy maker optimally accepts $50 \%$ more inflation volatility to reduce the volatility of the real rate by a similar share. Taking the risk-taking channel into account generates welfare gains for consumers between $0.5 \%$ and $1 \%$. 


\section{References}

Stephane Adjemian, Matthieu Darracq Paries, and Stephane Moyen. Towards a monetary policy evaluation framework. Working Paper Series 0942, European Central Bank, September 2008.

Tobias Adrian and Hyun Song Shin. Procyclical Leverage and Value-at-Risk. Review of Financial Studies, 27(2):373-403, 2014.

Tobias Adrian, Nina Boyarchenko, and Hyun Song Shin. The cyclicality of leverage. Staff Reports 743, Federal Reserve Bank of New York, October 2015.

Elena Afanasyeva and Jochen Guentner. Lending Standards, Credit Booms, and Monetary Policy. Technical report, mimeo, July 2015.

Edward Altman, Andrea Resti, and Andrea Sironi. Default Recovery Rates in Credit Risk Modeling: A Review of the Literature and Empirical Evidence. Working Paper Series S-CDM-03-11, NYU Working Paper, December 2003.

Ignazio Angeloni and Ester Faia. Capital regulation and monetary policy with fragile banks. Journal of Monetary Economics, 60(3):311-324, April 2013.

Ignazio Angeloni, Ester Faia, and Marco Lo Duca. Monetary policy and risk taking. Journal of Economic Dynamics and Control, 52:285-307, March 2015.

Charles Bean, Christian Broda, Takatoshi Ito, and Randall Kroszner. Low for Long? Causes and Consequences of Persistently Low Interest Rates. 17th cepricmb geneva report on the world economy, CERP, October 2015.

Ben S. Bernanke and Mark Gertler. Should Central Banks Respond to Movements in Asset Prices? American Economic Review, 91(2):253-257, May 2001.

Ben S. Bernanke, Mark Gertler, and Simon Gilchrist. The financial accelerator in a quantitative business cycle framework. In John B. Taylor and Michael D. Woodford, editors, Handbook of Macroeconomics, volume 1 of Handbook of Macroeconomics, chapter 21, pages 1341-1393. Elsevier, 1999.

Claudio Borio and Haibin Zhu. Capital regulation, risk-taking and monetary policy: a missing link in the transmission mechanism? (268), Dec 2008.

Claudia M. Buch, Sandra Eickmeier, and Esteban Prieto. In search for yield? Survey-based evidence on bank risk taking. Journal of Economic Dynamics and Control, 43(C):12-30, 2014.

Guillermo A. Calvo. Staggered Prices in a Utility-Maximizing Framework. Journal of Monetary Economics, 12(3):383-398, September 1983. 
Ian Christensen, Cesaire Meh, and Kevin Moran. Bank Leverage Regulation and Macroeconomic Dynamics. Working Papers 11-32, Bank of Canada, 2011.

Fabrice Collard, Harris Dellas, Behzad Diba, and Olivier Loisel. Optimal Monetary and Prudential Policies. Technical report, 2012.

Fiorella De Fiore and Oreste Tristani. Optimal Monetary Policy in a Model of the Credit Channel. Economic Journal, 123(571):906-931, 092013.

Oliver de Groot. The Risk Channel of Monetary Policy. International Journal of Central Banking, 10(2):115-160, June 2014.

Giovanni Dell'Ariccia, Luc Laeven, and Gustavo Suarez. Bank Leverage and Monetary Policy's Risk-Taking Channel: Evidence from the United States. Working Paper 13/143, IMF, June 2013.

Giovanni Dell'Ariccia, Luc Laeven, and Robert Marquez. Real interest rates, leverage, and bank risk-taking. Journal of Economic Theory, 149(0):65 - 99, 2014 .

Asli Demirgüç-Kunt, Baybars Karacaovali, and Luc Laeven. Deposit Insurance Around the World: A Comprehensive Database. World Bank Policy Research Working Paper 3628, 2005.

Mark Gertler, Nobuhiro Kiyotaki, and Albert Queralto. Financial crises, bank risk exposure and government financial policy. Journal of Monetary Economics, 59 (S):S17-S34, 2012.

Vasso Ioannidou, Steven Ongena, and Jose-Lui Peydro. Monetary Policy, RiskTaking and Pricing: Evidence from a Quasi-Natural Experiment. Discussion Paper 2009-04S, European Banking Center, June 2014.

Harold Jeffreys. Theory of Probability. Oxford University Press, Oxford, 3rd edition, 1961.

Gabriel Jimenez, Steven Ongena, Jose Luis Peydro, and Jesus Saurina. Hazardous Times for Monetary Policy: What Do Twenty-Three Million Bank Loans Say About the Effects of Monetary Policy on Credit Risk-Taking? Econometrica, 82(2):463-505, 2014.

Alejandro Justiniano, Giorgio E. Primiceri, and Andrea Tambalotti. Investment shocks and the relative price of investment. Review of Economic Dynamics, 14 (1):102-121, 2011.

Robert E. Kass and Adrian E. Raftery. Bayes factors. Journal of the American Statistical Association, 90(430):773-795, 1995. 
Miles S. T. Kimball. The Quantitative Analytics of the Basic Neomonetarist Model. Journal of Money, Credit and Banking, 27(4):1241-77, November 1995.

Andrew T.. Levin, Volker Wieland, and John Williams. Robustness of Simple Monetary Policy Rules under Model Uncertainty. In Monetary Policy Rules, NBER Chapters, pages 263-318. National Bureau of Economic Research, Inc, September 1999.

Rajnish Mehra and Edward C. Prescott. The equity premium: A puzzle. Journal of Monetary Economics, 15(2):145-161, March 1985.

Stephanie Schmitt-Grohe and Martin Uribe. Optimal, Simple, and Implementable Monetary and Fiscal Rules . Journal of Monetary Economics, 54(6):1702-1725, September 2007.

Patrick Slovik. Systemically important banks and capital regulation challenges. Technical report, OECD, 2012.

Frank Smets and Rafael Wouters. Shocks and Frictions in US Business Cycles: A Bayesian DSGE Approach. American Economic Review, 97(3):586-606, 2007.

Jeremy Stein. Overheating in credit markets: Origins, measurement, and policy responses, 2013. Remarks by Governor Jeremy Stein At the "Restoring Household Financial Stability after the Great Recession: Why Household Balance Sheets Matter" research symposium sponsored by the Federal Reserve Bank of St. Louis, St. Louis, Missouri.

John B. Taylor. Housing and monetary policy. Proceedings - Economic Policy Symposium - Jackson Hole, pages 463-476, 2007.

Michael Woodford. Inflation Targeting and Optimal Monetary Policy . The Federal Reserve Bank of St. Louis Review, 90(430):15-42, 2004. 


\section{Appendix A: Data description}

Table 3: All level variables are expressed in per-capita terms (divided by $N$ ). Hours are measured as $H_{1} \cdot H_{2} / N$ where $H_{1}$ is converted into an index. The nominal wage $W$ is deflated by the GDP deflator. We define equity capital as equity plus reserves plus subordinated debt, and total liabilities as equity plus deposits. To do do, we net out two types of liabilities, since they are typically overcollateralized: federal funds purchased \& repurchase agreements and federal home loan bank advances. Furthermore, we omit a few categories of debt that match neither of our concepts of insured deposits and equity, or that are simply not enough characterized: other borrowed money, uncategorized liabilities, trading book liabilities, banks liability on acceptances. All of these balance sheet positions are minor. Over the observation period, the first group accounts for roughly $11 \%$ of the balance sheet, the second for about $9 \%$. All indexes are adjusted such that $2009=100$. The estimation sample spans from 1984Q1 to 2007Q3. Our survey-based proxy for bank risk-taking $q$, is constructed using data from the US Terms of Business Lending Survey. The survey provides the internal risk rating assigned by banks to newly issued loans. In this survey, available from 1997Q1 onwards, 400 banks report the volume of loans originated in the first week of the mid month each quarter, grouped by internal risk rating. This rating varies between 1 and 5, with 5 being the maximum level of risk. Following Dell'Ariccia et al. (2014), we construct a weighted average loan risk series, using as weights the value of loans in each risk category.

\begin{tabular}{|c|c|c|c|c|}
\hline SYMBOL & SERIES & MNEMONIC & UNIT & SOURCE \\
\hline$Y$ & REAL GROSS DOMESTIC PRODUCT & GDPC96 & BN. USD & FRED / BEA \\
\hline$P$ & GDP DEFLATOR & GDPDEF & INDEX & FRED / BEA \\
\hline$R$ & EFFECTIVE FEDERAL FUNDS RATE & FEDFUNDS & $\%$ & FRED / BOARD OF GOVERNORS \\
\hline$C$ & PERSONAL CONSUMPTION EXPENDITURE & PCEC & BN. USD & FRED / BEA \\
\hline$I$ & FIXED PRIVATE INVESTMENT & FPI & BN. USD & FRED / BEA \\
\hline$H_{1}$ & CIVILIAN EMPLOYMENT & CE16ov & THOUSANDS & FRED / BLS \\
\hline $\mathrm{H}_{2}$ & NONFARM BUSINESS (..) HOURS & PRS85006023 & INDEX & DEPARTMENT OF LABOR \\
\hline$W$ & NONFARM BUSINESS (..) HOURLY COMPENSATION & PRS85006103 & INDEX & DEPARTMENT OF LABOR \\
\hline$N$ & CIVILIAN POPULATION & LNS1000000 & 0CE16ov & BLS \\
\hline$q$ & AVERAGE WEIGHTED LOAN RISK & own calculation & $\%$ & BOARD OF GOVERNORS \\
\hline$E$ & EQUITY CAPITAL OVER LIABILITIES & own calculation & $\%$ & FDIC \\
\hline
\end{tabular}

\section{Appendix B: The full model; equilibrium and estimation} details

This Appendix outlines the set-up of the conventional parts of the model. Furthermore, it defines the equilibrium, listing all model equations, grouped by sector.

The Households' problem: Households maximize their lifetime utility function: 


$$
\max _{d_{t}, e_{t}, s_{t}, c_{t}, L_{t}} E\left[\sum_{t=0}^{\infty} \beta^{t} \varepsilon_{t}^{B} \frac{\left(c_{t}-\iota c_{t-1}\right)^{1-\sigma_{C}}}{1-\sigma_{C}} \exp \left(\varphi L_{t}^{1+\sigma_{L}} \frac{\sigma_{C}-1}{1+\sigma_{L}}\right)\right]
$$

subject to the per-period budget constraint in real terms:

$$
c_{t}+d_{t}+e_{t}+s_{t}+T_{t}=L_{t} w_{t}+d_{t-1} \frac{R_{d, t}}{\pi_{t}}+e_{t-1} \frac{R_{e, t}}{\pi_{t}}+s_{t-1} \frac{R_{t-1}}{\pi_{t}}+\Pi_{t},
$$

where $\pi_{t}$ is the inflation rate, while $T_{t}$ and $\Pi_{t}$ are taxes and profits from firm ownership, expressed in real terms. We allow for habits in consumption $(\iota)$ and a time preference shock $\varepsilon_{t}^{B}$. This shock is assumed to be persistent with log-normal innovations, like all following shocks unless otherwise specified. The household's optimality conditions are given by the usual Euler equation, two no-arbitrage conditions and the labor supply condition:

$$
\begin{aligned}
\Lambda_{t} & =\beta E_{t}\left[\Lambda_{t+1} \frac{R_{t}}{\pi_{t+1}}\right], \\
E_{t}\left[\Lambda_{t+1} \frac{R_{d, t+1}}{\pi_{t+1}}\right] & =E_{t}\left[\Lambda_{t+1} \frac{R_{t}}{\pi_{t+1}}\right], \\
E_{t}\left[\Lambda_{t+1} \frac{R_{e, t+1}}{\pi_{t+1}}\right] & =E_{t}\left[\Lambda_{t+1} \frac{R_{t}}{\pi_{t+1}}\right], \\
\Lambda_{t} w_{t} & =\frac{\left(c_{t}-\iota c_{t-1}\right)^{1-\sigma_{C}}}{1-\sigma_{C}} \exp \left(\varphi L_{t}^{1+\sigma_{L}} \frac{\sigma_{C}-1}{1+\sigma_{L}}\right)\left(1-\sigma_{C}\right) L_{t}^{\sigma_{L}}
\end{aligned}
$$

where $\Lambda_{t}=\varepsilon_{t}^{B}\left(c_{t}-\iota c_{t-1}\right)^{-\sigma_{C}}-\beta \iota E_{t}\left[\varepsilon_{t+1}^{B}\left(c_{t+1}-\iota c_{t}\right)^{-\sigma_{C}}\right]$ is the marginal utility of consumption.

Labor and goods sectors: Final goods producers assemble different varieties of intermediate goods through a Kimball (1995) aggregator with elasticity of substitution $\epsilon_{p}$ and Kimball parameter $k_{p}$, taking as given both the final good price and the prices of intermediate goods. Their optimization problem yields demand functions for each intermediate good variety as a function of its relative price.

A continuum of firms produces differentiated intermediate goods using capital $K_{t-1}$ and "packed" labor $l_{t}^{d}$ as inputs. The production function is Cobb-Douglas and is affected by a total factor productivity shock $\varepsilon_{t}^{A}$. Firms use their monopolistic power to set prices, taking as given their demand schedule. As in Calvo (1983), they can reset their prices in each period with probability $\lambda^{p}$, otherwise they index their prices to past inflation with degree $\gamma^{p}$ and to steady-state inflation with degree 
$\left(1-\gamma^{p}\right)$. Furthermore, they are subject to a time-varying mean-zero revenue tax $\varepsilon_{t}^{p}$ that is equivalent to a markup shock, up to a first-order approximation. ${ }^{57}$

The labor market resembles the product market. Packed labor is produced by labor packers, who aggregate differentiated labor services using a Kimball (1995) aggregator with elasticity of substitution $\epsilon_{w}$ and Kimball parameter $k_{w}$.

Differentiated labor services are produced by a continuum of unions from the households labor supply. They use their monopolistic power to set wages. Wages are reset with probability $\lambda^{w}$, otherwise they are indexed to past inflation (with degree $\gamma^{w}$ ) and steady-state inflation. Like intermediate firms, unions are subject to a stochastic wage tax $\varepsilon_{t}^{w}{ }^{58}$

See the Appendix of Smets and Wouters (2007) for a detailed discussion of the set-up and Adjemian et al. (2008) for the recursive formulation of the equilibrium conditions, which we list below.

Monetary and fiscal policy: The central bank follows a nominal interest rate rule, targeting inflation and output deviations from the steady state:

$$
R_{t}-\bar{R}=(1-\rho)\left(\phi_{\pi} \hat{\pi}_{t}+\phi_{y} \hat{y}_{t}\right)+\rho\left(R_{t-1}-\bar{R}\right)+\varepsilon_{t}^{R}
$$

where $\rho$ is a smoothing parameter, the hat symbol denotes percentage deviations from the steady-state values, $\bar{R}=\frac{\pi_{s s}}{\beta}$ is the steady-state nominal interest rate, and $\varepsilon_{t}^{R}$ is a monetary policy shock. In addition, the fiscal authority finances a stochastic expenditure stream $g_{y} \bar{Y} \varepsilon_{t}^{G}$ :

$$
\ln \left(\varepsilon_{t}^{G}\right)=\rho_{g} \ln \left(\varepsilon_{t-1}^{G}\right)+u_{t}^{G}+\rho_{G A} u_{t}^{A}
$$

where we allow for a correlation between exogenous spending and innovations to total factor productivity. ${ }^{59}$ For simplicity, we rule out government debt $\left(s_{t}=0\right)$, implying that all expenditures are financed by lump sum taxes; i.e. $g_{y} \bar{Y} \varepsilon_{t}^{G}=T_{t}$.

Competitive equilibrium: The competitive equilibrium is a path of 43 variables $\left(\Lambda, K, L, y, l, c, q, k, d, e, \pi, r_{k}, r_{d}, r_{e}, R, W, m c, o^{n e w}, o, \pi^{\star}, Z_{p 1}, Z_{p 2}\right.$, $Z_{p 3}, Z_{w 1}, Z_{w 2}, Z_{w 3}, \Delta_{p 1}, \Delta_{p 2}, \Delta_{p 3}, \Delta_{p 4}, \Delta_{w 1}, \Delta_{w 2}, \Delta_{w 3} \Delta_{w 4}, \tau_{p}, \tau_{w}, W^{\star}, i, \tilde{R}, \xi, \tilde{\xi}$, $\tilde{\psi}, \tau)$ that satisfy the following 41 equations at each point in time, given initial conditions and the exogenous shock processes $\varepsilon^{A}, \varepsilon^{B}, \varepsilon^{G}, \varepsilon^{I}, \varepsilon^{P}, \varepsilon^{R}, \varepsilon^{W}, \varepsilon^{\xi}$.

\footnotetext{
${ }^{57}$ Unlike a true markup shock, this tax allows for a recursive representation of the nonlinear problem.

${ }^{58}$ Both $\varepsilon_{t}^{p}$ and $\varepsilon_{t}^{w}$ follow the standard shock process augmented by an moving average component, as in Smets and Wouters (2007).

${ }^{59}$ This is a shortcut to take exports into account. Productivity innovations might raise exports in the data, and a way to capture it in a closed-economy model such as ours is to allow for
} 


\section{Household $^{60}$}

$$
\begin{gathered}
\Lambda_{t}=\varepsilon_{t}^{B}\left(c_{t}-\iota c_{t-1}\right)^{-\sigma_{C}}-\beta \iota E_{t}\left[\varepsilon_{t+1}^{B}\left(c_{t+1}-\iota c_{t}\right)^{-\sigma_{C}}\right] \\
E_{t}\left[\Lambda_{t+1} \frac{q_{t} r_{d, t+1}+\left(1-q_{t}\right) \frac{\psi}{1-k_{t}} \pi_{t+1}}{\pi_{t+1}}\right]=E_{t}\left[\Lambda_{t+1} \frac{R_{t}}{\pi_{t+1}}\right] \\
E_{t}\left[\Lambda_{t+1} \frac{q_{t} r_{e, t+1}-\xi_{t} \pi_{t+1}}{\pi_{t+1}}\right]=E_{t}\left[\Lambda_{t+1} \frac{R_{t}}{\pi_{t+1}}\right] \\
\Lambda_{t}=\beta E_{t}\left[\Lambda_{t+1} \frac{R_{t}}{\pi_{t+1}}\right] \\
y_{t}=c_{t}+i_{t}+g_{y} \bar{Y} \varepsilon_{t}^{G}
\end{gathered}
$$

\section{Goods sector}

$$
\begin{gathered}
\frac{L_{t}^{d}}{K_{t-1}} \frac{\alpha}{1-\alpha}=\frac{r_{k, t}}{w_{t}} \\
m c_{t}=\frac{1}{A_{t}} \alpha^{-\alpha} r_{k t}^{\alpha} w_{t}^{1-\alpha}(1-\alpha)^{\alpha-1} \\
\pi_{t}^{\star}=\frac{\epsilon_{p}\left(1+k_{p}\right)}{\epsilon_{p}\left(1+k_{p}\right)-1} \frac{Z_{p 1, t}}{Z_{p 2, t}}+\frac{k_{p}}{\epsilon_{p}-1}\left(\pi_{t}^{\star}\right)^{1+\epsilon_{p}\left(1+k_{p}\right)} \frac{Z_{p 3, t}}{Z_{p 2, t}} \\
Z_{p 1, t}=\Lambda_{t} m c_{t} y_{t} \Delta_{p 1, t}^{\epsilon_{p}\left(1+k_{p}\right) /\left(1-\epsilon_{p}\left(1+k_{p}\right)\right)}+\beta \lambda_{p} E_{t}\left[\left(\frac{\pi_{t+1}}{\pi_{t}^{\gamma_{p}} \bar{\pi}^{1-\gamma_{p}}}\right)^{\epsilon_{p}\left(1+k_{p}\right)} Z_{p 1, t+1}\right] \\
Z_{p 2, t}=\left(1-\tau_{p, t}\right) \Lambda_{t} y_{t} \Delta_{p 1, t}^{\epsilon_{p}\left(1+k_{p}\right) /\left(1-\epsilon_{p}\left(1+k_{p}\right)\right)}+\beta \lambda_{p} E_{t}\left[\left(\frac{\pi_{t+1}^{\gamma_{p}} \bar{\pi}^{1-\gamma_{p}}}{\pi_{t}}\right)^{\epsilon_{p}\left(1+k_{p}\right)-1}\right. \\
Z_{p 3, t}=\left(1-\tau_{p, t}\right) \Lambda_{t} y_{t}+\beta \lambda_{p} E_{t}\left[\left(\frac{\pi_{t+1}^{\gamma_{p}} \bar{\pi}^{1-\gamma_{p}}}{1+k_{p}}\right)_{p 1, t}^{1 /\left(1-\epsilon_{p}\left(1+k_{p}\right)\right)}+\frac{k_{p}}{1+k_{p}} \Delta_{p 2, t}\right. \\
\Delta_{p 1, t}=\left(1-\lambda_{p}\right)\left(\pi_{t}^{\star}\right)^{1-\epsilon_{p}\left(1+k_{p}\right)}+\lambda_{p} \Delta_{p 1, t-1}\left(\frac{\pi_{t+1}^{\gamma_{p}} \bar{\pi}^{1-\gamma_{p}}}{\pi_{p}}\right)^{\epsilon_{p}\left(1+k_{p}\right)-1}
\end{gathered}
$$

${ }^{60}$ Note that $R^{d}$ and $R^{e}$ have been substituted out. The FOC w.r.t. labor is merged with the labor sector equations. 


$$
\begin{gathered}
\Delta_{p 2, t}=\left(1-\lambda_{p}\right) \pi_{t}^{\star}+\lambda_{p} \Delta_{p 2, t-1}\left(\frac{\pi_{t+1}}{\pi_{t}^{\gamma_{p}} \bar{\pi}^{1-\gamma_{p}}}\right)^{-1} \\
\Delta_{p 3, t}=\frac{1}{1+k_{p}} \Delta_{p 1, t}^{\epsilon_{p}\left(1+k_{p}\right) /\left(1-\epsilon_{p}\left(1+k_{p}\right)\right)} \Delta_{p 4, t}+\frac{k_{p}}{1+k_{p}} \\
\Delta_{p 4, t}=\left(1-\lambda_{p}\right)\left(\pi_{t}^{\star}\right)^{-\epsilon_{p}\left(1+k_{p}\right)}+\lambda_{p} \Delta_{p 4, t-1}\left(\frac{\pi_{t+1}}{\pi_{t}^{\gamma_{p}} \bar{\pi}^{1-\gamma_{p}}}\right)^{\epsilon_{p}\left(1+k_{p}\right)} \\
A_{t} K_{t-1}^{\alpha}\left(\frac{L_{t}}{\Delta_{p 3, t}}\right)^{1-\alpha}=\Delta_{p 3, t} y_{t} \\
1-\tau_{p, t}=\varepsilon_{p, t}
\end{gathered}
$$

\section{Labor sector}

$$
\begin{aligned}
& w_{t}^{\star}=\frac{\epsilon_{w}\left(1+k_{w}\right)}{\epsilon_{w}\left(1+k_{w}\right)-1} \frac{Z_{w 1, t}}{Z_{w 2, t}}+\frac{k_{w}}{\epsilon_{w}-1}\left(w_{t}^{\star}\right)^{1+\epsilon_{p}\left(1+k_{p}\right)} \frac{Z_{w 3, t}}{Z_{w 2, t}} \\
& Z_{w 1, t}=\varepsilon_{t}^{B} \bar{L} L_{t}^{1+\sigma_{L}} w_{t}^{\epsilon_{w}\left(1+k_{w}\right)}\left(C_{t}-\iota C_{t-1}\right)^{1-\sigma_{c}} \exp \left(\bar{L} \frac{\sigma_{c}-1}{1+\sigma_{l}} L_{t}^{1+\sigma_{L}}\right) \Delta_{w 1, t}^{\epsilon_{w}\left(1+k_{w}\right) /\left(1-\epsilon_{w}\left(1+k_{3}\right.\right.}(39) \\
& +\beta \lambda_{w} E_{t}\left[\left(\frac{\pi_{t+1}}{\pi_{t}^{\gamma_{w}} \bar{\pi}^{1-\gamma_{w}}}\right)^{\epsilon_{w}\left(1+k_{w}\right)} Z_{w 1, t}\right] \\
& Z_{w 2, t}=\left(1-\tau_{w, t}\right) \Lambda_{t} L_{t}\left[w_{t} \Delta_{w 1, t}^{1 /\left(1-\epsilon_{w}\left(1+k_{w}\right)\right)}\right]^{\epsilon_{w}\left(1+k_{w}\right)}+\beta \lambda_{w} E_{t}\left[\left(\frac{\pi_{t+1}}{\pi_{t}^{\gamma_{w}} \bar{\pi}^{1-\gamma_{w}}}\right)^{\epsilon_{w}\left(1+k_{w}\right)-1} Z_{w 2, t+1}\right] \\
& Z_{w 3, t}=\left(1-\tau_{w, t}\right) \Lambda_{t} L_{t}+\beta \lambda_{w} E_{t}\left[\left(\frac{\pi_{t+1}}{\pi_{t}^{\gamma_{p}} \bar{\pi}^{1-\gamma_{p}}}\right)^{-1} Z_{w 3, t+1}\right] \\
& \Delta_{w 1, t}=\left(1-\lambda_{w}\right)\left(\frac{w_{t}^{\star}}{w_{t}}\right)^{1-\epsilon_{w}\left(1+k_{w}\right)}+\lambda_{w} \Delta_{w 1, t-1}\left(\frac{w_{t-1}}{w_{t}}\right)^{1-\epsilon_{w}\left(1+k_{w}\right)}\left(\frac{\pi_{t+1}}{\pi_{t}^{\gamma_{w}} \bar{\pi}^{1-\gamma_{w}}}\right)^{\epsilon_{w}\left(1+k_{w}\right)-1} \\
& 1=\frac{1}{1+k_{w}} \Delta_{w 1, t}^{1 /\left(1-\epsilon_{w}\left(1+k_{w}\right)\right)}+\frac{k_{w}}{1+k_{w}} \Delta_{w 2, t} \\
& \Delta_{w 2, t}=\left(1-\lambda_{w}\right)\left(\frac{w_{t}^{\star}}{w_{t}}\right)+\lambda_{w} \Delta_{w 2, t-1}\left(\frac{w_{t}}{w_{t-1}} \frac{\pi_{t+1}}{\pi_{t}^{\gamma_{w}} \bar{\pi}^{1-\gamma_{w}}}\right)^{-1} \\
& \Delta_{w 3, t}=\frac{1}{1+k_{w}} \Delta_{w 1, t}^{\epsilon_{w}\left(1+k_{w}\right) /\left(1-\epsilon_{w}\left(1+k_{w}\right)\right)} \Delta_{w 4, t}+\frac{k_{w}}{1+k_{w}} \\
& \Delta_{w 4, t}=\left(1-\lambda_{w}\right)\left(\frac{w_{t}^{\star}}{w_{t}}\right)^{-\epsilon_{w}\left(1+k_{w}\right)}+\lambda_{w} \Delta_{w 4, t-1}\left(\frac{w_{t}}{w_{t-1}} \frac{\pi_{t+1}}{\pi_{t}^{\gamma_{w}} \bar{\pi}^{1-\gamma_{w}}}\right)^{\epsilon_{w}\left(1+k_{w}\right)}
\end{aligned}
$$




$$
1-\tau_{w, t}=\varepsilon_{w, t}
$$

\section{Government}

$$
R_{t}-\bar{R}=\phi_{\pi} \frac{\pi_{t+s}}{\bar{\pi}}+\phi_{y} \frac{y_{t+s}}{\bar{y}}+\phi_{k} \frac{k_{t+s}}{\bar{k}}+\rho\left(R_{t-1}-\bar{R}\right)
$$

\section{Capital producer}

$$
\begin{gathered}
K_{t}=q_{t}\left(\omega_{1}-\frac{\omega_{2}}{2} q_{t}\right) o_{t}+\left(1-q_{t}\right) \theta \\
o_{t}=o_{t}^{n e w}+(1-\delta) K_{t-1} \\
o_{t}^{n e w}=\varepsilon_{T}^{I} i_{t}\left(1-\frac{\kappa}{2}\left(\frac{i_{t}}{i_{t-1}}-1\right)^{2}\right) \\
Q_{t} \varepsilon_{t}^{I}\left[1-S\left(\frac{i_{t}}{i_{t-1}}\right)-S^{\prime}\left(\frac{i_{t}}{i_{t-1}}\right) \frac{i_{t}}{i_{t-1}}\right]-1=\beta E_{t}\left[\frac{\Lambda_{t+1}}{\Lambda_{t}} \varepsilon_{t+1}^{I} Q_{t+1} S^{\prime}\left(\frac{i_{t+1}}{i_{t}}\right)\left(\frac{i_{t+1}}{i_{t}}\right)^{2}\right] .
\end{gathered}
$$

\section{Bank}

$$
\begin{gathered}
q_{t}=1-\frac{\tilde{R}}{\tilde{\psi}_{t}}+\frac{\sqrt{\omega_{2}\left(\tilde{R}_{t}-\tilde{\psi}_{t}\right)\left(\tilde{R}_{t}+2 \tilde{\xi}_{t}\right)\left(2 \omega_{1} \tilde{\psi}_{t}\left(\tilde{R}_{t}+\tilde{\xi}_{t}\right)+\omega_{2}\left(\tilde{R}_{t}-\tilde{\psi}_{t}\right)\left(\tilde{R}_{t}+2 \tilde{\xi}_{t}\right)\right)}}{\omega_{2} \tilde{\psi}_{t}\left(\tilde{R}_{t}+2 \tilde{\xi}_{t}\right)} \\
k_{t}=\frac{\tilde{R}_{t}-\tilde{\psi}_{t}}{\tilde{R}_{t}+2 \tilde{\xi}_{t}} \\
\left(\omega_{1}-\frac{\omega_{2}}{2} q_{t-1}\right) \frac{r_{k, t}+(1-\delta) Q_{t}-\tau_{: t}}{Q_{t-1} \frac{r_{d, t}}{\pi_{t+1}}\left(1-k_{t}\right)-\frac{r_{e, t+1}}{\pi_{t+1}} k_{t}=0} \\
Q_{t-1} \frac{1-q_{t-1}}{q_{t-1}}\left(\psi-\theta \frac{r_{k, t}+(1-\delta) Q_{t}}{Q_{t-1}}\right) \\
\omega_{1}-\frac{\omega_{2}}{2} q_{t-1} \\
\tau_{t}=\frac{\xi_{t} E_{t}\left[\Lambda_{t+1}\right]}{\xi_{t}=\xi \varepsilon_{t}^{\xi}}
\end{gathered}
$$




$$
\begin{gathered}
\tilde{R}_{t}=E_{t}\left[\Lambda_{t+1} \frac{R_{t}}{\pi_{t+1}}\right] \\
\tilde{\psi}_{t}=\psi E_{t}\left[\Lambda_{t+1}\right] \\
o_{t} Q_{t}=e_{t}+d_{t} \\
k_{t}=e_{t} /\left(e_{t}+d_{t}\right)
\end{gathered}
$$

Shock processes

$$
\begin{gathered}
\log \left(\varepsilon_{t}^{B}\right)=\rho_{P} \log \left(\varepsilon_{t-1}^{B}\right)+\sigma^{B} u_{t}^{B} \\
\log \left(\varepsilon_{t}^{Q}\right)=\rho_{I} \log \left(\varepsilon_{t-1}^{Q}\right)+\sigma^{Q} u_{t}^{Q} \\
\log \left(\varepsilon_{t}^{\xi}\right)=\rho_{\xi} \log \left(\varepsilon_{t-1}^{\xi}\right)+\sigma^{\xi} u_{t}^{\xi} \\
\log \left(\varepsilon_{t}^{P}\right)=\rho_{P} \log \left(\varepsilon_{t-1}^{P}\right)+\sigma^{P}\left(u_{t}^{P}+m_{p} u_{t-1}^{P}\right) \\
\log \left(\varepsilon_{t}^{W}\right)=\rho_{W} \log \left(\varepsilon_{t-1}^{W}\right)+\sigma^{W}\left(u_{t}^{W}+m_{W} u_{t-1}^{W}\right) \\
\log \left(\varepsilon_{t}^{A}\right)=\rho_{A} \log \left(\varepsilon_{t-1}^{A}\right)+\sigma^{A} u_{t}^{A} \\
\log \left(\varepsilon_{t}^{R}\right)=\rho_{R} \log \left(\varepsilon_{t-1}^{R}\right)+\sigma^{R} u_{t}^{R} \\
\log \left(\varepsilon_{t}^{G}\right)=\rho_{G} \log \left(\varepsilon_{t-1}^{G}\right)+\sigma^{G} u_{t}^{G}+\rho_{G A} \sigma^{A} u_{t}^{A}
\end{gathered}
$$

Observational equations: The observation equations, linking the observed time series (left hand-side) to the variables in the non-linear model (right handside) are the following:

$$
\begin{aligned}
100 \Delta \log \left(\frac{Y_{t}}{Y_{t-1}}\right) & =100 \Delta \log \left(\frac{y_{t}}{y_{t-1}}\right)+100 \mu_{y} \\
100 \Delta \log \left(\frac{C_{t}}{C_{t-1}}\right) & =100 \Delta \log \left(\frac{c_{t}}{c_{t-1}}\right)+100 \mu_{y} \\
100 \Delta \log \left(\frac{I_{t}}{I_{t-1}}\right) & =100 \Delta \log \left(\frac{i_{t}}{i_{t-1}}\right)+100 \mu_{y} \\
100 \Delta \log \left(\frac{W_{t}}{W_{t-1}}\right) & =100 \Delta \log \left(\frac{w_{t}}{w_{t-1}}\right)+100 \mu_{y}
\end{aligned}
$$




$$
\begin{gathered}
100 \Delta \log \left(\frac{P_{t}}{P_{t-1}}\right)=100 \pi_{t} \\
100 \log \left(\frac{H_{t}}{\bar{H}}\right)=100 \log \left(\frac{L_{t}}{\bar{L}}\right)+100 \mu_{l} \\
\left(\frac{R_{t}}{4}\right)=100 R \\
\tilde{E}_{t}=100 k_{t}
\end{gathered}
$$

where $\bar{H}$ are hours worked in 2009 and $\mu_{l}$ is a shift parameter. Since there is no growth in the model, we estimate the mean growth rate in the data $\mu_{y}$. The equity ratio in the data $\tilde{E}_{t}$ is transformed by taking deviations from its linear trend and adding back the mean.

Prior specifications: We fix parameters that are not identified to values commonly used in the literature. In particular, we choose a depreciation rate $\delta$ of 0.025, a steady-state wage markup $\bar{\varepsilon}^{W}$ of 1.05 , a steady-state spending to GDP ratio $g_{y}$ of $18 \%$, a weight of labor in the utility function $\bar{L}$ such that steady-state hours are equal to 1, and curvatures of the Kimball aggregator for goods and labor varieties of 10 .

For all structural shocks, we employ a non-informative uniform distribution. The persistences of the shock processes are assumed to have a beta prior distribution centered at 0.5, and with standard deviation of 0.2. Following Smets and Wouters (2007), we further assume that the two markup shows have a moving average component.

The priors of the Taylor rule parameters are centered around very common values: the smoothing parameter has a Beta distribution with a mean of 0.75 , while the responses to inflation and output are assumed to follow a Normal distribution with a mean of 1.5 and of $0.5 / 4=0.125$.

Since we use level data of the inflation rate and of the nominal interest rate, we choose the priors for the steady state of the inflation rate $\bar{\pi}$ and the real interest rate $1 / \beta-1$ to match the mean in the data, i.e. we assumed they follow a gamma distribution respectively centered around annualized values of $2.5 \%$ and 0.9 .

The parameters affecting price and wage stickiness have a beta distribution centered at 0.5 with standard deviation of 0.1 . Our prior is that prices and wages are reoptimized on average every 6 months, and that the degree of indexation to past inflation is only up to $50 \%$. The steady-state price markup is assumed to be centered around 1.25, slightly above the steady-state wage markup. 
We employ very common priors for all the parameters of the utility function. Habits are centered around 0.7, the intertemporal elasticity of substitution $\sigma_{c}$ has a prior mean of 1.5, while the elasticity of labor supply $\sigma_{l}$ has a prior mean of 2. The capital share in production has a prior mean of 0.3 while the investment adjustment costs parameter has a loose prior around 4 .

For the discussion on the priors for the banking sector parameters, we refer to the main text.

Estimation The estimation was done in DYNARE. We verify that all estimated parameters are separately identifiable. The mode is computed using csminwel. Experiments with the computation of the mode did not reveal problems of multimodality. For the Metropolis-Hastings algorithm we set the scale parameter such as to obtain a acceptance ratio of around $30 \%$ and use two parallel chains of length $2,000,000$, which was found to be enough for convergence. The recovered shock series are well behaved.

\section{Appendix C: Proofs}

\section{The risk-taking channel for a generic expected return func- tion}

Consider the bank problem discussed in Section 2, but replace the expression for the expected return conditional on success $q_{t}\left(\omega_{1}-\omega_{2} / 2 q_{t}\right)$ with the generic function $f\left(q_{t}\right)$.

Assume there exists an equilibrium $\left[\tilde{r}_{l, t}, q_{t}, k_{t}\right]$ under perfect competition that satisfies the following conditions: (1) the bank's choices are interior, i.e. $\left[k_{t}, q_{t}\right] \in$ $[0,1]^{2}$, (2a) the default probability is low relative to the parameters $\frac{q_{t}}{\left(1-q_{t}\right)} \tilde{\xi}_{t} \geq$ $\tilde{R}_{t}-\tilde{\psi}_{t}$ or $(2 \mathrm{~b})$ there is no deposit insurance $\tilde{\psi}_{t}=0$, the conditional expected return function $f\left(q_{t}\right)$ satisfies $(3) f\left(q_{t}\right) \geq 0, f^{\prime \prime}\left(q_{t}\right)<0$ and $(4) f^{\prime \prime \prime}\left(q_{t}\right) \leq 0$, $f^{\prime \prime \prime \prime}\left(q_{t}\right) \leq 0$.

Note that assumption 2a), which is sufficient but by no means necessary and only needed for claim (e), is weak if we consider the empirically relevant section of the parameter space with a low equity premium (around 0.0x), a real rate just above $1(1.0 \mathrm{x})$ and high level of deposit insurance (0.x) and high repayment probabilities $(0.9 \mathrm{x})$. Assumption 3 is straightforward as it guarantees a meaningful risk return trade-off with an interior solution. Assumption 4 is another sufficient but non-necessary condition.

We prove that if such a solution exists, then: risk taking is excessive: $q_{t}<\operatorname{argmax} f\left(q_{t}\right)$, the safety of assets $q_{t}$ is a positive function of $\tilde{R}_{t}: \frac{\partial q_{t}}{\partial \tilde{R}_{t}}>0$, 
Table 4: Model estimation: prior and posterior values

\begin{tabular}{|c|c|c|c|c|c|c|c|}
\hline & parameter & prior shape & prior mean & prior std & post. mean & \multicolumn{2}{|c|}{$90 \%$ HPD interval } \\
\hline \multicolumn{8}{|c|}{ structural parameters } \\
\hline$\mu_{y}$ & trend growth & norm & 0.4 & 0.1 & 0.4264 & 0.3908 & 0.4618 \\
\hline$\mu_{l}$ & labor normalization & norm & 0 & 2 & -0.0938 & -1.6569 & 1.4777 \\
\hline$\alpha$ & output share & norm & 0.3 & 0.05 & 0.2001 & 0.1602 & 0.2395 \\
\hline $100 \frac{1-\beta}{\beta}$ & real rate in $\%$ & norm & 0.25 & 0.1 & 0.427 & 0.2992 & 0.5485 \\
\hline $\bar{\varepsilon}^{P}$ & price markup & norm & 1.25 & 0.12 & 1.5068 & 1.3621 & 1.6523 \\
\hline $\bar{\pi}$ & inflation in \% & gamma & 0.62 & 0.1 & 0.6263 & 0.4893 & 0.7616 \\
\hline$\phi_{\pi}$ & TR weight on inflation & norm & 1.5 & 0.25 & 1.8723 & 1.5489 & 2.2003 \\
\hline$\phi_{y}$ & TR weight on output & norm & 0.12 & 0.05 & 0.0198 & -0.0348 & 0.0753 \\
\hline$\rho$ & TR persistence & beta & 0.75 & 0.1 & 0.8411 & 0.8057 & 0.8768 \\
\hline$\kappa$ & investment adj. costs & norm & 4 & 1.5 & 7.4584 & 5.5992 & 9.3376 \\
\hline$\iota$ & habits & norm & 0.7 & 0.1 & 0.7774 & 0.7042 & 0.8532 \\
\hline$\sigma_{c}$ & risk aversion & gamma & 1.5 & 0.375 & 1.7362 & 1.2809 & 2.1939 \\
\hline$\sigma_{l}$ & disutility from labor & gamma & 2 & 0.75 & 2.0183 & 0.9726 & 3.0566 \\
\hline$\lambda_{p}$ & price calvo parameter & beta & 0.5 & 0.1 & 0.6206 & 0.5429 & 0.701 \\
\hline$\lambda_{w}$ & wage calvo parameter & beta & 0.5 & 0.1 & 0.8476 & 0.8099 & 0.8864 \\
\hline$\gamma_{p}$ & price indexation & beta & 0.5 & 0.15 & 0.1533 & 0.0537 & 0.2479 \\
\hline$\gamma_{w}$ & wage indexation & beta & 0.5 & 0.15 & 0.448 & 0.2066 & 0.6829 \\
\hline$\xi$ & equity premium & norm & 0.015 & 0.01 & 0.0213 & 0.0054 & 0.0348 \\
\hline$\theta$ & liquidation value & norm & 0.5 & 0.1 & 0.7416 & 0.6425 & 0.8385 \\
\hline $\bar{k}$ & equity ratio & norm & 0.12 & 0.05 & 0.1231 & 0.1208 & 0.1254 \\
\hline \multicolumn{8}{|c|}{ structural shock processes } \\
\hline$\sigma_{A}$ & stdev TFP & unif & 0 & 10 & 0.3665 & 0.3172 & 0.414 \\
\hline$\sigma_{B}$ & stdev preference & unif & 0 & 10 & 3.4696 & 2.2271 & 4.6946 \\
\hline$\sigma_{G}$ & stdev govt. spending & unif & 0 & 10 & 2.2678 & 1.984 & 2.5382 \\
\hline$\sigma_{I}$ & stdev investment & unif & 0 & 10 & 4.7269 & 3.0495 & 6.3757 \\
\hline$\sigma_{P}$ & stdev price markup & unif & 0 & 1 & 0.1332 & 0.109 & 0.1574 \\
\hline$\sigma_{R}$ & stdev monetary & unif & 0 & 1 & 0.1164 & 0.1009 & 0.1315 \\
\hline$\sigma_{W}$ & stdev wage markup & unif & 0 & 10 & 0.4742 & 0.4088 & 0.5389 \\
\hline$\sigma_{\xi}$ & stdev equity premium & unif & 0 & 10 & 0.5805 & 0.199 & 1.0255 \\
\hline$\rho_{A}$ & persistence TFP & beta & 0.5 & 0.2 & 0.4623 & 0.3496 & 0.5765 \\
\hline$\rho_{B}$ & persistence preference & beta & 0.5 & 0.2 & 0.9004 & 0.8549 & 0.9486 \\
\hline$\rho_{G}$ & $\begin{array}{l}\text { persistence gov. } \\
\text { spending }\end{array}$ & beta & 0.5 & 0.2 & 0.9009 & 0.8471 & 0.9556 \\
\hline$\rho_{I}$ & persistence investment & beta & 0.5 & 0.2 & 0.1924 & 0.0357 & 0.3396 \\
\hline$\rho_{P}$ & persistence price markup & beta & 0.5 & 0.2 & 0.9772 & 0.9625 & 0.9925 \\
\hline$\rho_{R}$ & persistence monetary & beta & 0.5 & 0.2 & 0.9585 & 0.918 & 0.9967 \\
\hline$\rho_{W}$ & persistence wage markup & beta & 0.5 & 0.2 & 0.7721 & 0.6706 & 0.8734 \\
\hline$\rho_{\xi}$ & $\begin{array}{l}\text { persistence equity } \\
\text { premium }\end{array}$ & beta & 0.5 & 0.2 & 0.8156 & 0.7623 & 0.8699 \\
\hline$\rho_{G, A}$ & $\begin{array}{l}\text { correlation gov. } \\
\text { spending \& TFP }\end{array}$ & beta & 0.5 & 0.2 & 0.6513 & 0.3835 & 0.9394 \\
\hline$m_{p}$ & $\begin{array}{l}\text { MA component of price } \\
\text { markup }\end{array}$ & beta & 0.5 & 0.2 & 0.7765 & 0.6826 & 0.875 \\
\hline$m_{w}$ & $\begin{array}{l}\text { MA component of wage } \\
\text { markup }\end{array}$ & beta & 0.5 & 0.2 & 0.9741 & 0.9516 & 0.9972 \\
\hline
\end{tabular}


(c) the equity ratio $k_{t}$ is a positive function of $\tilde{R}_{t}: \frac{\partial k_{t}}{\partial \tilde{R}_{t}}>0$,

(d) the expected return on investment is a positive function of $\tilde{R}_{t}: \frac{\partial f\left(q_{t}\left(\tilde{R}_{t}\right)\right)+\left(1-q_{t}\left(\tilde{R}_{t}\right)\right) \theta}{\partial \tilde{R}_{t}}>$ 0 ,

(e) the expected return on investment is a concave function of $\tilde{R}_{t}: \frac{\partial^{2} f\left(q_{t}\left(\tilde{R}_{t}\right)\right)+\left(1-q_{t}\left(\tilde{R}_{t}\right)\right) \theta}{\partial \tilde{R}_{t}^{2}}<$ 0 .

For a generic return function $f\left(q_{t}\right)$ the bank's objective function at the second stage is:

$$
\max _{q_{t}} f\left(q_{t}\right) \tilde{r}_{l, t}-q_{t} \tilde{r}_{d, t}\left(1-k_{t}\right)
$$

Deriving this problem with respect to $q_{t}$ yields the following first-order condition, which by concavity is necessary and sufficient:

$$
f^{\prime}\left(q_{t}\right) \tilde{r}_{l, t}=\tilde{r}_{d, t}\left(1-k_{t}\right)
$$

Notice that this condition implies $f^{\prime}\left(q_{t}\right)>0\left(k_{t} \in(0,1]\right.$ by assumption, $\tilde{r}_{d, t}>0$ by the deposit supply schedule, and $\tilde{r}_{l, t}>0$ by the zero-profit condition). Notice further that in a frictionless world, e.g. without limited liability, the bank's risk choice would satisfy $q_{t}^{o p t}=\operatorname{argmax} f\left(q_{t}\right)+\left(1-q_{t}\right) \theta$, i.e. $f^{\prime}\left(q_{t}^{\text {opt }}\right)=\theta$. Since we have assumed above that the recovery value is smaller than the deposit insurance cap, which in turn is smaller than the cost of deposits by lemma 1, we have: $\tilde{r}_{l, t} \theta<\tilde{\psi}_{t}<\tilde{r}_{d, t}\left(1-k_{t}\right)$. Combining this with equation (71) and the frictionless optimality condition and rearranging, we obtain $f^{\prime}\left(q_{t}\right)>f^{\prime}\left(q_{t}^{\text {opt }}\right)$. Given $f^{\prime \prime}\left(q_{t}\right)<0$ this implies excessive risk taking, i.e. $q_{t}<q_{t}^{o p t}$ (claim(a)).

Since the deposit supply schedule must hold in equilibrium, we can rewrite this condition as:

$$
f^{\prime}\left(q_{t}\right) \tilde{r}_{l, t}-\frac{\tilde{R}_{t}\left(1-k_{t}\right)+\left(1-q_{t}\right) \tilde{\psi}_{t}}{q_{t}}=0
$$

Equation (72) implicitly defines $\hat{q}_{t}\left(k_{t}\right)$. Using the implicit function theorem we find that, $f^{\prime}\left(q_{t}^{o p t}\right)=\theta<\tilde{r}_{d, t}\left(1-k_{t}\right)=f^{\prime}\left(q_{t}\right) \tilde{r}_{l, t}$

$$
\frac{\partial q_{t}}{\partial k_{t}}=\frac{-q_{t} \tilde{R}_{t}}{\left(1-k_{t}\right) \tilde{R}_{t}-\tilde{\psi}_{t}+q_{t}^{2} \tilde{r}_{l, t} f^{\prime \prime}\left(q_{t}\right)}
$$

At the first stage the maximization problem is:

$$
\max _{k_{t}} f\left(q_{t}\right) \tilde{r}_{l, t}-q_{t} \tilde{r}_{d, t}\left(1-k_{t}\right)-q_{t} k_{t} \tilde{r}_{e, t}
$$

which, using the deposit and equity supply schedules $\tilde{r}_{d, t}=\frac{\tilde{R}_{t}-\frac{1-q_{t}}{1-k_{t}} \tilde{\psi}_{t}}{q_{t}} \tilde{r}_{e, t}=\frac{\tilde{R}_{t}+\tilde{\xi}_{t}}{q_{t}}$, can be written as: 


$$
\max _{k_{t}} f\left(\hat{q}_{t}\right) \tilde{r}_{l, t}+\left(1-q_{t}\right) \tilde{\psi}_{t}-k_{t} \tilde{\xi}_{t}-\tilde{R}_{t}
$$

The corresponding FOC is:

$$
\left(f^{\prime}\left(\hat{q}_{t}\right) \tilde{r}_{l, t}-\tilde{\psi}_{t}\right) \frac{\partial q_{t}}{\partial k_{t}}-\tilde{\xi}_{t}
$$

Finally, the zero-profit condition can in expectations be written as:

$$
f\left(\hat{q}_{t}\right) \tilde{r}_{l, t}+\left(1-q_{t}\right) \tilde{\psi}_{t}-k_{t} \tilde{\xi}_{t}-\tilde{R}_{t}
$$

Equations (72), (73), (74) implicitly define $q_{t}, k_{t}$ and $\tilde{r}_{l, t}$. Solving the latter two equations for $k_{t}$ and $\tilde{r}_{l, t}$ we obtain:

$$
\begin{gathered}
k_{t}=\frac{\left(-\tilde{\xi}_{t} \tilde{R}_{t}+q_{t} \tilde{R}_{t} \tilde{\psi}_{t}+\tilde{\xi}_{t} \tilde{\psi}_{t}\right) f\left(q_{t}\right)-q_{t}\left(\tilde{R}_{t}-\left(1-q_{t}\right) \tilde{\psi}_{t}\right)\left(\tilde{R}_{t} f^{\prime}\left(q_{t}\right)+q_{t} \tilde{\xi}_{t} f^{\prime \prime}\left(q_{t}\right)\right)}{-\tilde{\xi}_{t}\left(\tilde{R}_{t} f\left(q_{t}\right)-q_{t}\left(\tilde{R}_{t} f^{\prime}\left(q_{t}\right)+q_{t} \tilde{\xi}_{t} f^{\prime \prime}\left(q_{t}\right)\right)\right)} \\
\tilde{r}_{l, t}=\frac{\left(\tilde{R}_{t}+\tilde{\xi}_{t}\right)\left(\tilde{R}_{t}-\tilde{\psi}_{t}\right)}{\tilde{R}_{t} f\left(q_{t}\right)-q_{t}\left(\tilde{R}_{t} f^{\prime}\left(q_{t}\right)+q_{t} \tilde{\xi}_{t} f^{\prime \prime}\left(q_{t}\right)\right)}
\end{gathered}
$$

Plugging these equations into (72) and rearranging, we obtain the following equation, which implicitly defines $q_{t}$ :

$$
\left(\tilde{R}_{t}+\tilde{\xi}_{t}\right) \frac{\tilde{R}_{t} \tilde{\psi}_{t} f\left(q_{t}\right)-\left(\tilde{R}_{t}\left(\tilde{R}_{t}+\tilde{\xi}_{t}\right)-\left(\left(1-q_{t}\right) \tilde{R}_{t}+\tilde{\xi}_{t}\right) \tilde{\psi}_{t}\right) f^{\prime}\left(q_{t}\right)-q_{t} \tilde{\xi}_{t}\left(\tilde{R}_{t}-\left(1-q_{t}\right) \tilde{\psi}_{t}\right) f^{\prime \prime}\left(q_{t}\right)}{-\tilde{\xi}_{t}\left(\tilde{R}_{t} f\left(q_{t}\right)-q_{t}\left(\tilde{R}_{t} f^{\prime}\left(q_{t}\right)+q_{t} \tilde{\xi}_{t} f^{\prime \prime}\left(q_{t}\right)\right)\right)}=0
$$

We can simplify this condition further by multiplying by the denominator and dividing by $\left(\tilde{R}_{t}+\tilde{\xi}_{t}\right) \tilde{R}_{t}$ :

$$
F\left(q_{t}, R_{t}\right) \equiv \frac{\tilde{R}_{t} \tilde{\psi}_{t} f\left(q_{t}\right)-\left(\tilde{R}_{t}\left(\tilde{R}_{t}+\tilde{\xi}_{t}\right)-\left(\left(1-q_{t}\right) \tilde{R}_{t}+\tilde{\xi}_{t}\right) \tilde{\psi}_{t}\right) f^{\prime}\left(q_{t}\right)-q_{t} \tilde{\xi}_{t}\left(\tilde{R}_{t}-\left(1-q_{t}\right) \tilde{\psi}_{t}\right) f^{\prime \prime}\left(q_{t}\right)}{\tilde{R}_{t}}=0
$$

Using the implicit function theorem on equation (77), we find that :

$$
\frac{\partial q_{t}}{\partial R_{t}}=-\frac{\frac{\partial F}{\partial R_{t}}}{\frac{\partial F}{\partial q_{t}}}
$$

where

$$
\begin{gathered}
\frac{\partial F}{\partial R_{t}}=\frac{\left(\tilde{R}_{t}^{2}+\tilde{\xi}_{t} \tilde{\psi}_{t}\right) f^{\prime}\left(q_{t}\right)+\left(1-q_{t}\right) q_{t} \tilde{\xi}_{t} \tilde{\psi}_{t} f^{\prime \prime}\left(q_{t}\right)}{-\tilde{R}_{t}^{2}} \\
\frac{\partial F}{\partial q_{t}}=\frac{\left(\tilde{R}_{t}-\left(1-q_{t}\right) \tilde{\psi}_{t}\right)\left(\left(\tilde{R}_{t}+2 \tilde{\xi}_{t}\right) f^{\prime \prime}\left(q_{t}\right)+q_{t} \tilde{\xi}_{t} f^{\prime \prime \prime}\left(q_{t}\right)\right)}{-\tilde{R}_{t}}
\end{gathered}
$$

Using our assumptions on $f$, the parameters and assuming an interior solution, it is obvious that $\frac{\partial F}{\partial q_{t}}>0$. How about the $\frac{\partial F}{\partial R_{t}}$ ?

To get the sign of $\frac{\partial F}{\partial R_{t}}$, we solve 77 for $f\left(q_{t}\right)$ :

$$
f\left(q_{t}\right)=\frac{\left(\tilde{R}_{t}\left(\tilde{R}_{t}+\tilde{\xi}_{t}\right)-\left(\left(1-q_{t}\right) \tilde{R}_{t}+\tilde{\xi}_{t}\right) \tilde{\psi}_{t}\right) f^{\prime}\left(q_{t}\right)+q_{t} \tilde{\xi}_{t}\left(\tilde{R}_{t}-\left(1-q_{t}\right) \tilde{\psi}_{t}\right) f^{\prime \prime}\left(q_{t}\right)}{\tilde{R}_{t} \tilde{\psi}_{t}}
$$


Using our assumptions on $f$, the parameters and assuming an interior solution, it is obvious that $\frac{\partial F}{\partial q_{t}}>0$. How about the $\frac{\partial F}{\partial R_{t}}$ ?

To get the sign of $\frac{\partial F}{\partial R_{t}}$, we solve 77 for $f\left(q_{t}\right)$ :

$$
f\left(q_{t}\right)=\frac{\left(\tilde{R}_{t}\left(\tilde{R}_{t}+\tilde{\xi}_{t}\right)-\left(\left(1-q_{t}\right) \tilde{R}_{t}+\tilde{\xi}_{t}\right) \tilde{\psi}_{t}\right) f^{\prime}\left(q_{t}\right)+q_{t} \tilde{\xi}_{t}\left(\tilde{R}_{t}-\left(1-q_{t}\right) \tilde{\psi}_{t}\right) f^{\prime \prime}\left(q_{t}\right)}{\tilde{R}_{t} \tilde{\psi}_{t}}
$$

and plug this expression into the equations (75) and (76) for $k_{t}$ and $\tilde{r}_{l, t}$ :

$$
\begin{gathered}
k_{t}=\frac{f^{\prime}\left(q_{t}\right)\left(\tilde{R}_{t}+\tilde{\xi}_{t}\right)\left(\tilde{R}_{t}-\tilde{\psi}_{t}\right)+f^{\prime \prime}\left(q_{t}\right) q_{t} \tilde{\xi}_{t}\left(\tilde{R}_{t}-\left(1-q_{t}\right) \tilde{\psi}_{t}\right)}{\tilde{R}_{t}\left(\left(\tilde{R}_{t}+\tilde{\xi}_{t}\right) f^{\prime}\left(q_{t}\right)+q_{t} \tilde{\xi}_{t} f^{\prime \prime}\left(q_{t}\right)\right)^{2}} \\
\tilde{r}_{l, t}=\frac{\left(\tilde{R}_{t}+\tilde{\xi}_{t}\right) \tilde{\psi}_{t}}{\left(\tilde{R}_{t}+\tilde{\xi}_{t}\right) f^{\prime}\left(q_{t}\right)+q_{t} \tilde{\xi}_{t} f^{\prime \prime}\left(q_{t}\right)}
\end{gathered}
$$

Since in equilibrium $\tilde{r}_{l, t}>0$ and since the numerator of $\tilde{r}_{l, t}$ is positive, it must hold that its denominator is also positive:

$$
\left(\tilde{R}_{t}+\tilde{\xi}_{t}\right) f^{\prime}\left(q_{t}\right)+q_{t} \tilde{\xi}_{t} f^{\prime \prime}\left(q_{t}\right)>0
$$

Similarly, since $k_{t}>0$ and since the denominator of $k_{t}$ is positive, the numerator must be positive too:

$$
f^{\prime}\left(q_{t}\right)\left(\tilde{R}_{t}+\tilde{\xi}_{t}\right)\left(\tilde{R}_{t}-\tilde{\psi}_{t}\right)+f^{\prime \prime}\left(q_{t}\right) q_{t} \tilde{\xi}_{t}\left(\tilde{R}_{t}-\left(1-q_{t}\right) \tilde{\psi}_{t}>0\right.
$$

Since $f^{\prime}>0$ and $f^{\prime \prime}<0$ we can conclude from the previous inequality that for any $\left[x_{1}, x_{2}\right] \in \mathbb{R}^{2}$ it must hold that $f^{\prime}\left(q_{t}\right) x_{1}+f^{\prime \prime}\left(q_{t}\right) x_{2}>0$ if

$$
\frac{x_{1}}{x_{2}} \geq \frac{\left(\tilde{R}_{t}+\tilde{\xi}_{t}\right)\left(\tilde{R}_{t}-\tilde{\psi}_{t}\right)}{q_{t} \tilde{\xi}_{t}\left(\tilde{R}_{t}-\left(1-q_{t}\right) \tilde{\psi}_{t}\right)} .
$$

We now test this condition for the numerator of $\frac{\partial F}{\partial R_{t}}$ :

$$
\frac{\tilde{R}_{t}^{2}+\tilde{\xi}_{t} \tilde{\psi}_{t}}{\left(1-q_{t}\right) q_{t} \tilde{\xi}_{t} \tilde{\psi}_{t}} \lessgtr \frac{\left(\tilde{R}_{t}+\tilde{\xi}_{t}\right)\left(\tilde{R}_{t}-\tilde{\psi}_{t}\right)}{q_{t} \tilde{\xi}_{t}\left(\tilde{R}_{t}-\left(1-q_{t}\right) \tilde{\psi}_{t}\right)} .
$$

Rearranging, multiplying only by positive values, yields:

$$
0 \lessgtr-\tilde{R}_{t}\left(\tilde{R}_{t}-\left(1-q_{t}\right) \tilde{\psi}_{t}\right)-q_{t} \tilde{\psi}_{t} \tilde{\xi}_{t}-\left(\tilde{R}_{t}\left(1-q_{t}\right) \tilde{\psi}_{t}+\left(1-q_{t}\right) \tilde{\psi}_{t} \tilde{\xi}_{t}\right) \frac{q_{t} \tilde{\psi}_{t}}{\left(\tilde{R}_{t}-\left(1-q_{t}\right) \tilde{\psi}_{t}\right)}
$$

The RHS is obviously negative since from the proposition that every deposit insurance cap will be exceeded, it follows that $\tilde{R}_{t}>\tilde{\psi}_{t}$. Hence the condition $\frac{\tilde{R}_{t}^{2}+\tilde{\xi}_{t} \tilde{\psi}_{t}}{\left(1-q_{t}\right) q_{t} \tilde{\xi}_{t} \tilde{\psi}_{t}} \geq \frac{\tilde{R}_{t}+\tilde{\xi}_{t}}{q_{t} \tilde{\xi}_{t}}$ is satisfied and we can conclude that the numerator of $\frac{\partial F}{\partial R_{t}}$ is positive. Hence $\frac{\partial F}{\partial R_{t}}<0$ and therefore $\frac{\partial q_{t}}{\partial R_{t}}>0$ (claim (b)).

Equation (79) defines $k_{t}=\mathfrak{K}\left(q_{t}, \tilde{R}_{t}\right)$. Its derivative is given by 


$$
\frac{\partial k_{t}}{\partial \tilde{R}_{t}}=\frac{\partial \mathfrak{K}}{\partial \tilde{R}_{t}}+\frac{\partial \mathfrak{K}}{\partial q_{t}} \frac{\partial q_{t}}{\partial \tilde{R}_{t}}
$$

where

$$
\begin{gathered}
\frac{\partial \mathfrak{K}}{\partial \tilde{R}_{t}}=\frac{\left(\left(f^{\prime}\left(q_{t}\right)\right)^{2} \tilde{R}_{t}^{2}+2 f^{\prime}\left(q_{t}\right)\left(f^{\prime}\left(q_{t}\right)+f^{\prime \prime}\left(q_{t}\right)\left(1-q_{t}\right) q_{t}\right) \tilde{R}_{t} \tilde{\xi}_{t}+\left(f^{\prime}\left(q_{t}\right)+f^{\prime \prime}\left(q_{t}\right) q_{t}\right)\left(f^{\prime}\left(q_{t}\right)-f^{\prime \prime}\left(q_{t}\right)\left(1-q_{t}\right) q_{t}\right) \tilde{\xi}_{t}^{2}\right) \tilde{\psi}_{t}}{\tilde{R}_{t}^{2}\left(f^{\prime \prime} q \tilde{\xi}_{t}+f^{\prime}\left(\tilde{R}_{t}+\tilde{\xi}_{t}\right)\right)^{2}} \\
\frac{\partial \mathfrak{K}}{\partial q_{t}}=\frac{q \tilde{\xi}_{t} f^{\prime \prime}\left(q_{t}\right) \tilde{\psi}_{t}\left(2\left(\tilde{R}_{t}+\tilde{\xi}_{t}\right) f^{\prime}\left(q_{t}\right)+q_{t} \tilde{\xi}_{t} f^{\prime \prime}\left(q_{t}\right)\right)}{\tilde{R}_{t}\left(f^{\prime \prime} q \tilde{\xi}_{t}+f^{\prime}\left(\tilde{R}_{t}+\tilde{\xi}_{t}\right)\right)^{2}}
\end{gathered}
$$

From (83) it is immediately obvious that the numerator of $\frac{\partial \mathfrak{K}}{\partial q_{t}}$ is negative, hence $\frac{\partial \mathfrak{K}}{\partial q_{t}}<0$. After division by $\tilde{\psi}_{t}$, the numerator of $\frac{\partial \mathfrak{K}}{\partial \tilde{R}_{t}}$ can be rewritten as:

$$
\left(\left(\tilde{R}_{t}+\tilde{\xi}_{t}\right) f^{\prime}\left(q_{t}\right)+q_{t} \tilde{\xi}_{t} f^{\prime \prime}\left(q_{t}\right)\right)^{2}-\left(f^{\prime \prime}\left(q_{t}\right)\right)^{2} q_{t}^{3} \tilde{\xi}_{t}^{2}-f^{\prime \prime}\left(q_{t}\right) f^{\prime}\left(q_{t}\right) q_{t}^{2} \tilde{\xi}_{t}\left(2 \tilde{R}_{t}+\tilde{\xi}_{t}\right)
$$

Since the first term is positive and larger than the absolute value of the second term we can see that $\frac{\partial \mathfrak{R}}{\partial \tilde{R}_{t}}>0$. Hence we have shown that $\frac{\partial k_{t}}{\partial \tilde{R}_{t}}>0$ (claim (c)).

Applying the implicit function theorem a second time on equation (77), we can find the following expression for the second derivative of $q_{t}$ :

$$
\frac{\partial^{2} q_{t}}{\partial \tilde{R}_{t}^{2}}=\frac{\left(\frac{\partial^{2} F}{\partial R_{t} \partial q_{t}}+\frac{\partial^{2} F}{\partial q_{t}^{2}} \frac{\partial q_{t}}{\partial R_{t}}\right) \frac{\partial F}{\partial R_{t}}-\left(\frac{\partial^{2} F}{\partial R_{t} \partial q_{t}} \frac{\partial q_{t}}{\partial R_{t}}+\frac{\partial^{2} F}{\partial R_{t}^{2}}\right) \frac{\partial F}{\partial q_{t}}}{\left(\frac{\partial F}{\partial q_{t}}\right)^{2}}
$$

where:

$$
\frac{\partial^{2} F}{\partial \tilde{R}_{t} \partial q_{t}}=\frac{\left(\tilde{R}_{t}^{2}+2\left(1-q_{t}\right) \tilde{\xi}_{t} \tilde{\psi}_{t}\right) f^{\prime \prime}\left(q_{t}\right)+q_{t}\left(1-q_{t}\right) \tilde{\xi}_{t} \tilde{\psi}_{t} f^{\prime \prime \prime}\left(q_{t}\right)}{-\tilde{R}_{t}}
$$

$\frac{\partial^{2} F}{\partial q_{t}^{2}}=\frac{\tilde{\psi}_{t}\left(q_{t} \tilde{\xi}_{t} f^{\prime \prime \prime}\left(q_{t}\right)+\left(\tilde{R}_{t}+2 \tilde{\xi}_{t}\right) f^{\prime \prime}\left(q_{t}\right)\right)+\left(f^{\prime \prime \prime \prime}\left(q_{t}\right) q_{t} \tilde{\xi}_{t}+f^{\prime \prime \prime}\left(q_{t}\right)\left(\tilde{R}_{t}+3 \tilde{\xi}_{t}\right)\right)\left(\tilde{R}_{t}-\left(1-q_{t}\right) \tilde{\psi}_{t}\right)}{-\tilde{R}_{t}}$

$$
\frac{\partial^{2} F}{\partial R_{t}^{2}}=\frac{2\left(f^{\prime}\left(q_{t}\right)+f^{\prime \prime}\left(q_{t}\right)(1-q) q\right) \tilde{\xi}_{t} \tilde{\psi}_{t}}{\tilde{R}_{t}^{3}}
$$

since $f^{\prime \prime}<0$ and $f^{\prime \prime \prime} \leq 0 f^{\prime \prime \prime \prime} \leq 0$ and all parameters are positive, it is obvious that $\frac{\partial^{2} F}{\partial R_{t} \partial q_{t}}>0$ and $\frac{\partial^{2} F}{\partial q_{t}^{2}}>0$. The term $\frac{\partial^{2} F}{\partial R_{t}^{2}}$ is less straightforward. A sufficient condition for $\frac{\partial^{2} F}{\partial R_{t}^{2}}>0$ can be found using condition (83):

$$
\frac{1}{\left(1-q_{t}\right) q_{t}} \geq \frac{\left(\tilde{R}_{t}+\tilde{\xi}_{t}\right)\left(\tilde{R}_{t}-\tilde{\psi}_{t}\right)}{q_{t} \tilde{\xi}_{t}\left(\tilde{R}_{t}-\left(1-q_{t}\right) \tilde{\psi}_{t}\right)}
$$


which simplifies to:

$$
\frac{q_{t}}{\left(1-q_{t}\right)} \tilde{\xi}_{t} \geq \tilde{R}_{t}-\tilde{\psi}_{t}
$$

Given the signs of the terms in (84) we have finally verified that:

$$
\frac{\partial^{2} q_{t}}{\partial \tilde{R}_{t}^{2}}=\frac{((+)+(+)(+))(-)-((+)(+)+(+))(+)}{(+)}<0
$$

Under alternative assumption (2b) the expression for $\frac{\partial^{2} q_{t}}{\partial \tilde{R}_{t}^{2}}$ simplifies to:

$$
\frac{\partial^{2} q_{t}}{\partial \tilde{R}_{t}^{2}}=-\frac{f^{\prime}\left(q_{t}\right)\left(-2 f^{\prime \prime}\left(q_{t}\right) f^{\prime \prime \prime}\left(q_{t}\right) q_{t} \tilde{\xi}_{t}-2\left(f^{\prime \prime}\left(q_{t}\right)\right)^{2}\left(\tilde{R}_{t}+2 \tilde{\xi}_{t}\right)+f^{\prime}\left(q_{t}\right)\left(f^{\prime \prime \prime \prime}\left(q_{t}\right) q_{t} \tilde{\xi}_{t}+f^{\prime \prime \prime}\left(q_{t}\right)\left(\tilde{R}_{t}+3 \tilde{\xi}_{t}\right)\right)\right)}{\left(f^{\prime \prime \prime}\left(q_{t}\right) \tilde{\xi}_{t}+f^{\prime \prime}\left(q_{t}\right)\left(\tilde{R}_{t}+2 \tilde{\xi}_{t}\right)\right)^{3}}
$$

which is negative without further conditions.

Using the signs of the derivatives of $q_{t}$ and the fact that $f^{\prime}\left(q_{t}\right)>f^{\prime}\left(q_{t}^{\text {opt }}\right)=\theta$, we can finally determine the slope and curvature of the expected return on the bank's investment.

$$
\begin{gathered}
\frac{\partial\left[f\left(q_{t}\right)+\left(1-\left(q_{t}\right)\right) \theta\right]}{\partial \tilde{R}_{t}}=\underbrace{\left(f^{\prime}\left(q_{t}\right)-\theta\right)}_{+} \underbrace{\frac{\partial q_{t}}{\partial \tilde{R}_{t}}}_{+}>0 \\
\frac{\partial^{2}\left[f\left(q_{t}\right)+\left(1-\left(q_{t}\right)\right) \theta\right]}{\partial \tilde{R}_{t}^{2}}=\underbrace{\left(f^{\prime}\left(q_{t}\right)-\theta\right)}_{+} \underbrace{\frac{\partial^{2} q_{t}}{\partial \tilde{R}_{t}^{2}}}_{+}+\underbrace{f^{\prime \prime}\left(q_{t}\right)}_{-} \underbrace{\frac{\partial q_{t}}{\partial \tilde{R}_{t}}}_{+}<0
\end{gathered}
$$

This completes the proof of claims (d) and (e).

Notice that the quadratic functional form we assumed for $f\left(q_{t}\right)$ in the model Section satisfies assumptions (3) and (4) and we focused on interior solutions (assumption (1)). Therefore claims (1), (2), (3) and (4) in propositions 1 and 2 hold. Furthermore, claim (5) in proposition 1 holds since assumption (2a) is satisfied. Finally, to see that claim (5) in proposition 2.1 holds independent of assumption (2a) and $(2 \mathrm{~b})$, consider the solution for $q_{t}$

$$
q_{t}=1-\frac{\tilde{R}}{\tilde{\psi}_{t}}+\frac{\sqrt{\omega_{2}\left(\tilde{R}_{t}-\tilde{\psi}_{t}\right)\left(\tilde{R}_{t}+2 \tilde{\xi}_{t}\right)\left(2 \omega_{1} \tilde{\psi}_{t}\left(\tilde{R}_{t}+\tilde{\xi}_{t}\right)+\omega_{2}\left(\tilde{R}_{t}-\tilde{\psi}_{t}\right)\left(\tilde{R}_{t}+2 \tilde{\xi}_{t}\right)\right)}}{\omega_{2} \tilde{\psi}_{t}\left(\tilde{R}_{t}+2 \tilde{\xi}_{t}\right)}
$$

The second derivative of this expression is:

$$
\begin{gathered}
\omega_{1} \omega_{2}\left\{2 \omega_{2}\left(\tilde{R}_{t}-\tilde{\psi}_{t}\right)^{3} \tilde{\xi}_{t}\left(\tilde{R}_{t}+2 \tilde{\xi}_{t}\right)+\omega_{1} \tilde{\psi}_{t} \ldots\right. \\
\frac{\partial^{2} q}{\partial \tilde{R}_{t}^{2}}=-\frac{\left.\ldots\left[\tilde{R}_{t}^{4}+2 \tilde{R}_{t}\left(4 \tilde{R}_{t}^{2}-3 \tilde{R}_{t} \tilde{\psi}_{t}+2 \tilde{\psi}_{t}^{2} \tilde{\xi}_{t}\right)+\left(12 \tilde{R}_{t}-4 \tilde{R}_{t} \tilde{\psi}_{t}+5 \tilde{\psi}_{t}^{2}\right) \tilde{\xi}_{t}^{2}+8 \tilde{R}_{t}+4 \tilde{\psi}_{t} \tilde{\xi}_{t}^{3}+16 \tilde{\xi}_{t}^{4}\right]\right\}}{\left(\tilde{R}_{t}+2 \tilde{\xi}_{t}\right)\left\{\omega_{2}\left(\tilde{R}_{t}-\tilde{\psi}_{t}\right)\left(\tilde{R}_{t}+2 \tilde{\xi}_{t}\right)\left[2 \omega_{1} \tilde{\psi}_{t}\left(\tilde{R}_{t}+\tilde{\xi}_{t}\right)+b\left(\tilde{R}_{t}-\tilde{\psi}_{t}\right)\left(\tilde{R}_{t}+2 \tilde{\xi}_{t}\right)\right]\right\}^{2 / 3}}
\end{gathered}
$$

Both the numerator and denominator are positive, so $\frac{\partial^{2} q}{\partial \tilde{R}_{t}^{2}}<0$. Hence $\frac{\partial^{2}\left[f\left(q_{t}\right)+\left(1-\left(q_{t}\right)\right) \theta\right]}{\partial \tilde{R}_{t}^{2}}<$ 0 . 


\section{Deposits in excess of insurance}

The proof is by contradiction: Assume that there exists an equilibrium with no excess profits where the bank would issue so little deposits that the promised repayment $r_{d, t}$ would be lower than the cap on deposit insurance $\psi /\left(1-k_{t}\right) \pi_{t+1}{ }^{61}$ In this case the deposit rate $r_{d, t}$ would be equal to the risk-free rate $R_{t}$.

The second-stage maximization problem of the bank would then be:

$$
\max _{q_{t} \in[0,1]} f\left(q_{t}\right) \tilde{r}_{l}-q_{t} \tilde{R}_{t}\left(1-k_{t}\right)
$$

and its solution $\hat{q}_{t}$ is implied by $f^{\prime}\left(q_{t}\right) \tilde{r}_{l}=\tilde{R}_{t}\left(1-k_{t}\right)$. The first-stage maximization problem is:

$$
\max _{k_{t} \in[0,1]} V(k)=f\left(\hat{q}_{t}\right) \tilde{r}_{l}-\hat{q} \tilde{R}_{t}\left(1-k_{t}\right)-\left(\tilde{\xi}_{t}+\tilde{R}_{t}\right) k_{t}
$$

$\hat{q}_{t}$ can either be a corner or an interior solution. If $\hat{q}_{t}$ is a corner solution, the first-stage objective function of the bank is obviously decreasing in $k_{t}$, hence $k_{t}=0$ is optimal. If $\hat{q}_{t}$ is an interior solution, the first derivative of the first-stage objective function is:

$$
-\tilde{\xi}_{t}-\tilde{R}_{t}\left(1-\hat{q}_{t}\right)
$$

Since $\hat{q}_{t} \in[0,1]$, this derivative is negative for all $k_{t} \in[0,1]$, i.e. the objective function is again decreasing in $\mathrm{k}$. Hence the solution to the first-stage problem is $k_{t}=0$. Optimality with full insurance therefore requires the bank to use only deposits. This contradicts our initial assumption. This result implies that any insurance cap smaller than $100 \%$ would be exceeded by the deposit liabilities in case of default. Depositors are therefore never fully insured.

Notice that for a cap to be effective in the sense of ruling out full insurance equilibria, the cap has to be low enough. Formally speaking, it needs to hold that $r_{d, t}\left(1-k_{t}\right)>\tilde{\psi}_{t}$ even under full insurance, i.e. $\tilde{R}_{t}>\tilde{\psi}_{t}$.

\footnotetext{
${ }^{61}$ For simplicity, we abstract from the possibility that the cap is binding for some states of the future but not for others, which would be possible due to the inconsistency between the timing of inflation and the nominal deposit rate. Note that this distinction disappears under certainty equivalence or first-order approximation.
} 


\section{Appendix D: Additional Tables}

These two tables reproduce tables 1 and 2. However, here we estimated the parameters for each model separately. I.e. the parameters of the two models differ and are chosen to fit each model to the same data. In the main text we used the parameters estimated for the bank model for both models.

Table 5: Optimal simple rules: The first (second) column describes the timing (restrictions) of the policy rule. The last row corresponds to a rule where only $\phi_{k}$ can be chosen and the other parameters are fixed to the optimized benchmark values. $V$ is the welfare level associated with each policy in the bank model. $\Omega$ is the welfare cost (in $\%$ of the consumption stream) associated with implementing in the bank model the optimal policy rule of the benchmark model. For the benchmark model the restriction $\phi_{k}=0$ is irrelevant, since the equity ratio is constant. Italics indicate restricted parameters. Notice that columns 6-10 (apart from the last line) are identical to Table 1.

\begin{tabular}{|c|c|c|c|c|c|c|c|c|c|c|}
\hline \multirow[b]{2}{*}{$s$} & \multirow[b]{2}{*}{ rule } & \multicolumn{3}{|c|}{ benchmark model } & \multirow[b]{2}{*}{$\rho$} & \multicolumn{3}{|c|}{ bank model } & \multirow[b]{2}{*}{$V$} & \multirow[b]{2}{*}{$\Omega$} \\
\hline & & $\rho$ & $\phi_{\pi_{t+s}}$ & $\phi_{y_{t+s}}$ & & $\phi_{\pi_{t+s}}$ & $\phi_{y_{t+s}}$ & $\phi_{k_{t}}$ & & \\
\hline 0 & $\phi_{k}, \rho=0$ & 0 & 8.088 & 0.117 & 0 & 3.080 & 0.126 & 0 & -185.321 & 0.658 \\
\hline 0 & $\phi_{k}=0$ & 0.000 & 8.088 & 0.117 & 1.059 & 0.510 & 0.005 & 0 & -184.750 & 1.081 \\
\hline 0 & $\rho=0$ & 0 & 8.088 & 0.117 & 0 & 2.637 & 0.097 & 0.027 & -185.314 & 0.663 \\
\hline 1 & $\phi_{k}, \rho=0$ & 0 & 23.070 & 0.101 & 0 & 4.294 & 0.172 & 0 & -185.209 & 1.093 \\
\hline 1 & $\phi_{k}=0$ & 0.213 & 17.463 & 0.101 & 1.114 & 0.072 & 0.074 & 0 & -184.656 & 1.176 \\
\hline 0 & choose $\phi_{k}$ & 0.000 & 8.088 & 0.117 & 0 & 8.088 & 0.117 & -0.177 & -185.453 & 0.560 \\
\hline
\end{tabular}

Table 6: Differences in moments associated with the optimal simple rules in the benchmark and in the bank model: This Table shows the \% differences in the mean and standard deviation associated with applying the different optimal rules in the bank model. The first entry, for example, indicates that under the optimal bank policy rule average risk would be 0.195\% lower than if the rule optimal for the benchmark model had been applied.

\begin{tabular}{cc|cccccc|ccccc}
\hline & & \multicolumn{6}{|c|}{ mean } & \multicolumn{5}{c}{ standard deviation } \\
$s$ & rule & $q$ & $R^{r}$ & $\pi$ & $y$ & $c$ & $f(q)$ & $q$ & $R^{r}$ & $\pi$ & $y$ & $c$ \\
\hline 0 & $\phi_{k}, \rho=0$ & 0.195 & 0.002 & -0.055 & 0.421 & 0.675 & 0.029 & -49.028 & -53.046 & 59.080 & -0.827 & -4.757 \\
0 & $\phi_{k}=0$ & 0.259 & 0.007 & -0.042 & 0.549 & 0.877 & 0.037 & -70.888 & -79.928 & 71.518 & -9.531 & -10.178 \\
0 & $\rho=0$ & 0.196 & 0.003 & -0.018 & 0.433 & 0.681 & 0.029 & -47.016 & -52.390 & 59.835 & -0.758 & -4.451 \\
1 & $\phi_{k}, \rho=0$ & 0.288 & 0.004 & -0.058 & 0.709 & 1.121 & 0.043 & -58.084 & -62.584 & 66.898 & -3.715 & -9.184 \\
1 & $\phi_{k}=0$ & 0.197 & 0.005 & 0.003 & 0.466 & 0.729 & 0.028 & -71.851 & -80.764 & 83.557 & -11.209 & -13.993 \\
0 & choose $\phi_{k}$ & 0.174 & 0.001 & -0.073 & 0.354 & 0.592 & 0.027 & -47.041 & -47.289 & 37.745 & 3.603 & -0.807 \\
\hline
\end{tabular}

This Table reproduces Table 2. However here we show the differences of the moments for each model assuming that in each model the central bank follows the respective optimal simple rule. 
Table 7: Differences in moments associated with the optimal simple rules in the benchmark and in the bank model: This Table shows the \% differences in the mean and standard deviation associated with applying the respective optimal simple rules in the benchmark and the bank model. The first entry, for example, indicates that under the optimal simple policy rule average risk is $0.15 \%$ lower in the bank model then in the benchmark model.

\begin{tabular}{cc|cccccc|ccccc}
\hline & & \multicolumn{9}{|c|}{ mean } & \multicolumn{5}{c}{ standard deviation } \\
$s$ & rule & $q$ & $R^{r}$ & $\pi$ & $y$ & $c$ & $f(q)$ & $q$ & $R^{r}$ & $\pi$ & $y$ & $c$ \\
\hline 0 & $\phi_{k}, \rho=0$ & 0.196 & 0.003 & -0.018 & 0.433 & 0.681 & 0.029 & -47.016 & -52.390 & 59.835 & -0.758 & -4.451 \\
0 & $\phi_{k}=0$ & 0.259 & 0.007 & -0.042 & 0.549 & 0.877 & 0.037 & -70.888 & -79.928 & 71.518 & -9.531 & -10.178 \\
0 & $\rho=0$ & 0.195 & 0.002 & -0.055 & 0.421 & 0.675 & 0.029 & -49.028 & -53.046 & 59.080 & -0.827 & -4.757 \\
1 & $\phi_{k}, \rho=0$ & 0.288 & 0.004 & -0.058 & 0.709 & 1.121 & 0.043 & -58.084 & -62.584 & 66.898 & -3.715 & -9.184 \\
1 & $\phi_{k}=0$ & 0.197 & 0.005 & 0.003 & 0.466 & 0.729 & 0.028 & -43.982 & -47.986 & 33.801 & 1.927 & -2.492 \\
0 & choose $\phi_{k}$ & 0.174 & 0.001 & -0.073 & 0.354 & 0.592 & 0.027 & -47.039 & -47.606 & 37.552 & 3.339 & -1.019 \\
\hline
\end{tabular}




\title{
BANCO DE ESPAÑA PUBLICATIONS
}

\author{
WORKING PAPERS
}

1701 JAVIER ANDRÉS, JAVIER J. PÉREZ and JUAN A. ROJAS: Implicit public debt thresholds: an empirical exercise for the case of Spain.

1702 LUIS J. ÁLVAREZ: Business cycle estimation with high-pass and band-pass local polynomial regression.

1703 ENRIQUE MORAL-BENITO, PAUL ALLISON and RICHARD WILLIAMS: Dynamic panel data modelling using maximum likelihood: an alternative to Arellano-Bond.

1704 MIKEL BEDAYO: Creating associations as a substitute for direct bank credit. Evidence from Belgium.

1705 MARÍA DOLORES GADEA-RIVAS, ANA GÓMEZ-LOSCOS and DANILO LEIVA-LEON: The evolution of regional economic interlinkages in Europe.

1706 ESTEBAN GARCÍA-MIRALLES: The crucial role of social welfare criteria for optimal inheritance taxation.

1707 MÓNICA CORREA-LÓPEZ and RAFAEL DOMÉNECH: Service regulations, input prices and export volumes: evidence from a panel of manufacturing firms.

1708 MARÍA DOLORES GADEA, ANA GÓMEZ-LOSCOS and GABRIEL PÉREZ-QUIRÓS: Dissecting US recoveries.

1709 CARLOS SANZ: Direct democracy and government size: evidence from Spain.

1710 HENRIQUE S. BASSO and JAMES COSTAIN: Fiscal delegation in a monetary union: instrument assignment and stabilization properties.

1711 IVÁN KATARYNIUK and JAIME MARTÍNEZ-MARTÍN: TFP growth and commodity prices in emerging economies.

1712 SEBASTIAN GECHERT, CHRISTOPH PAETZ and PALOMA VILLANUEVA: Top-down vs. bottom-up? Reconciling the effects of tax and transfer shocks on output.

1713 KNUT ARE AASTVEIT, FRANCESCO FURLANETTO and FRANCESCA LORIA: Has the Fed responded to house and stock prices? A time-varying analysis.

1714 FÁTIMA HERRANZ GONZÁLEZ and CARMEN MARTÍNEZ-CARRASCAL: The impact of firms' financial position on fixed investment and employment. An analysis for Spain.

1715 SERGIO MAYORDOMO, ANTONIO MORENO, STEVEN ONGENA and MARÍA RODRÍGUEZ-MORENO: "Keeping it personal" or "getting real"? On the drivers and effectiveness of personal versus real loan guarantees.

1716 FRANCESCO FURLANETTO and ØRJAN ROBSTAD: Immigration and the macroeconomy: some new empirical evidence.

1717 ALBERTO FUERTES: Exchange rate regime and external adjustment: an empirical investigation for the U.S.

1718 CRISTINA GUILLAMÓN, ENRIQUE MORAL-BENITO and SERGIO PUENTE: High growth firms in employment and productivity: dynamic interactions and the role of financial constraints.

1719 PAULO SOARES ESTEVES and ELVIRA PRADES: On domestic demand and export performance in the euro area countries: does export concentration matter?

1720 LUIS J. ÁLVAREZ and ANA GÓMEZ-LOSCOS: A menu on output gap estimation methods.

1721 PAULA GIL, FRANCISCO MARTÍ, JAVIER J. PÉREZ, ROBERTO RAMOS and RICHARD MORRIS: The output effects of tax changes: narrative evidence from Spain.

1722 RICARDO GIMENO and ALFREDO IBÁÑEZ: The eurozone (expected) inflation: an option's eyes view.

1723 MIGUEL ANTÓN, SERGIO MAYORDOMO and MARÍA RODRÍGUEZ-MORENO: Dealing with dealers: sovereign CDS comovements.

1724 JOSÉ MANUEL MONTERO: Pricing decisions under financial frictions: evidence from the WDN survey.

1725 MARIO ALLOZA: The impact of taxes on income mobility.

1726 DANILO LEIVA-LEON: Measuring business cycles intra-synchronization in US: a regime-switching interdependence framework.

1727 PIERRE GUÉRIN and DANILO LEIVA-LEON: Model averaging in Markov-Switching models: predicting national recessions with regional data.

1728 MÁXIMO CAMACHO and DANILO LEIVA-LEON: The propagation of industrial business cycles.

1729 JAMES COSTAIN: Costly decisions and sequential bargaining.

1730 MARIO ALLOZA: Is fiscal policy more effective in uncertain times or during recessions?

1731 PIERRE GUÉRIN and DANILO LEIVA-LEON: Monetary policy, stock market and sectoral comovement.

1732 HENRIK JENSEN, IVAN PETRELLA, SØREN HOVE RAVN and EMILIANO SANTORO: Leverage and deepening business cycle skewness.

1733 CÉSAR MARTÍN MACHUCA: External stress early warning indicators. 
1734 RODOLFO G. CAMPOS: International migration pressures in the long run.

1735 ANDREA ARIU, ELENA BIEWEN, SVEN BLANK, GUILLAUME GAULIER, MARÍA JESÚS GONZÁLEZ, PHILIPP MEINEN, DANIEL MIRZA, CÉSAR MARTÍN MACHUCA and PATRY TELLO: Firm heterogeneity and aggregate business services exports: micro evidence from Belgium, France, Germany and Spain.

1736 LEONARDO GAMBACORTA, STEFANO SCHIAFFI and ADRIAN VAN RIXTEL: Changing business models in international bank funding.

1737 ENRIQUE MORAL-BENITO and FRANCESCA VIANI: An anatomy of the Spanish current account adjustment: the role of permanent and transitory factors.

1738 MARÍA J. NIETO and LARRY D. WALL: Cross-border banking on the two sides of the Atlantic: does it have an impact on bank crisis management?

1739 JACOPO TIMINI: Currency unions and heterogeneous trade effects: the case of the Latin Monetary Union.

1740 PAULINO FONT, MARIO IZQUIERDO and SERGIO PUENTE: Subsidising mature age employment or throwing coins into a wishing well: a quasi-experimental analysis.

1741 THOMAS FUJIWARA and CARLOS SANZ: Norms in bargaining: evidence from government formation in Spain.

1742 ENRIQUE ALBEROLA, ÁNGEL ESTRADA and FRANCESCA VIANI: Global imbalances from a stock perspective.

1743 ÓSCAR ARCE, RICARDO GIMENO and SERGIO MAYORDOMO: Making room for the needy: the credit-reallocation effects of the ECB's corporate QE.

1744 M. D. GADEA-RIVAS, ANA GÓMEZ-LOSCOS and EDUARDO BANDRÉS: Clustering regional business cycles.

1745 NEZIH GUNER, YULIYA KULIKOVA and JOAN LLULL: Marriage and health: selection, protection, and assortative mating

1746 SERGIO MAYORDOMO and MARÍA RODRÍGUEZ-MORENO: Did the bank capital relief induced by the supporting factor enhance SME lending?

1747 KATALIN BODNÁR, LUDMILA FADEJEVA, MARCO HOEBERICHTS, MARIO IZQUIERDO PEINADO, CHRISTOPHE JADEAU and ELIANA VIVIANO: Credit shocks and the European Labour market.

1748 PIERRE GUÉRIN, DANILO LEIVA-LEON and MASSIMILIANO MARCELLINO: Markov-switching three-pass regression filter

1749 ISABEL ARGIMÓN: Decentralized multinational banks and risk taking: the Spanish experience in the crisis.

1750 BING XU: Permissible collateral and access to finance: evidence from a quasi-natural experiment.

1751 GERGELY AKOS GANICS: Optimal density forecast combinations.

1801 OLYMPIA BOVER, LAURA HOSPIDO and ERNESTO VILLANUEVA: The impact of high school financial education on financial knowledge and choices: evidence from a randomized trial in Spain.

1802 IGNACIO HERNANDO, IRENE PABLOS, DANIEL SANTABÁRBARA and JAVIER VALLÉS: Private Saving. New CrossCountry Evidence Based on Bayesian Techniques.

1803 PABLO AGUILAR and JESÚS VÁZQUEZ: Term structure and real-time learning.

1804 MORITZ A. ROTH: International co-movements in recessions.

1805 ANGELA ABBATE and DOMINIK THALER: Monetary policy and the asset risk-taking channel.

BANCODEESPAÑA

Eurosistema
Unidad de Servicios Auxiliares

Alcalá, 48 - 28014 Madrid

E-mail: publicaciones@bde.es www.bde.es 